\title{
Is there a euro effect in the drivers of US FDI? New evidence using Bayesian Model Averaging techniques*
}

\author{
Mariam Camarero ${ }^{\dagger}$ Sergi Moliner łand Cecilio Tamarit ${ }^{a \S}$
}

\begin{abstract}
In this paper we analyze the potential determinants of US outward FDI stock with a particular focus on the euro effect during the period 1985-2017. To this aim, we consider a large set of candidate variables suggested both theory and previous empirical analysis. We select the covariates using Bayesian Model Averaging (BMA), a data-driven methodology. Our sample includes a total of 56 host countries, that represent around the $70 \%$ of US outward FDI stock. We study the role of the euro on American FDI both in Europe and the rest of the world. In Europe, we consider various country groups: the European Union (EU), the Euro Area (EA), as well as core and periphery within this last group. We conclude that many variables studied by previous FDI literature cannot be considered robust determinants. Moreover, US OFDI is explained by both horizontal and vertical motives. However, HFDI strategies predominate in EA core countries, whereas VFDI prevails in the periphery. As for the euro effect, the common currency seems to have played an important role encouraging US FDI, being a crucial element in the convergence of EA periphery to its core. In addition, our results indicate that the adoption of the euro has favoured VFDI to the detriment of HFDI.
\end{abstract}

Keywords: FDI determinants; Foreign Direct Investment; US; European Union; Euro area; Bayesian Model Averaging; Variable selection

JEL classification: F21, F23, C11, C52

${ }^{*}$ The authors are grateful to Astrit Sulstarova for providing us with the extended version of FDI stock from the UNCTAD's Bilateral FDI Statistics database. Furthermore, we are indebted to Anabel Forte for her help using the BayesVarSel package. This paper has benefited from the comments of the participants in the KOF Euro20 workshop and, in particular from S. Maiani, J. de Haan, D. Furceri and J.E. Sturm. The authors acknowledge the public funding from the EU (ERDF, ESF) and the AEI-Spanish Ministry of Economy and Competitiveness ECO2017-83255-C3-3-P project, as well as the Valencian regional government (Generalitat Valenciana-PROMETEO 2018/102 project). Cecilio Tamarit and Mariam Camarero also acknowledge the funding from European Commission project 611032-EPP-1-2019-1-ES-EPPJMO-CoE. The European Commission support does not constitute an endorsement of the contents which reflects the views only of the authors, and the Commission cannot be held responsible for any use which may be made of the information contained therein. All remaining errors are ours.

${ }^{\dagger}$ University Jaume I and INTECO, Department of Economics, Campus de Riu Sec, E-12080 Castellón (Spain). ORCID: 0000-0003-4525-5181

łUniversity Jaume I and INTECO, Department of Economics, Campus de Riu Sec, E-12080 Castellón (Spain)

§a Corresponding author: University of València and INTECO, Department of Applied Economics II, Av. dels Tarongers, s/n Eastern Department Building E-46022 Valencia, Spain. email: Cecilio. Tamarit@uv . es ORCID: 0000-0002-0538-9882 


\section{Introduction and motivation}

The economic impact of regional integration in Europe has been a topic widely addressed in the literature. The main focus has been on the effects on trade, but some studies have also given insights into the role of the deepening of the European Union (EU) and, in particular, the creation of the Euro area (EA), have had on foreign direct investment (FDI).

The increased intra-European capital mobility has been one of the expected benefits derived from the adoption of a single currency; this effect may be explained by the following reasons. First, the elimination of intra-area currency risks and the reduction of country-risk premia encouraged significant cross-border capital flows within the Euro area. Second, the first years of the single European currency coincided with an unprecedented growth of global capital flows. Rapid technological changes and the gradual opening and liberalization of markets have notably contributed to the increase in international direct investment. Third, the euro has also coincided with an important EU enlargement process to the East.

Most of the empirical literature so far has focused on the study of intra-European FDI and the measurement of a possible EMU membership effect at an aggregate level, mostly on the impact for the EA as a whole. The consensus emerging from this literature is that the euro has been pro-FDI, in particular as regards intra FDI ${ }^{1}$. Baldwin et al. (2008) and Neary (2009) suggest that the Single Market programme and the euro adoption should be positive for intra-euro area vertical FDI (VFDI) due to the pro-trade effects of the Single Market integration and euro launching, but should discourage intra-euro area horizontal FDI (HFDI), as the single currency and Single Market integration reduce trade costs. Empirically, the positive effect appears to dominate as shown inter alia by Flam and Nordstrom (2008), Brouwer et al. (2008), or De Sousa and Lochard (2011). Baldwin et al. (2008) also conclude that the euro stimulates VFDI based on the observation that the euro's pro-FDI effect was much larger in manufacturing than it was in services ${ }^{2}$.

In this paper, we differ from most of the previous literature in that we analyze the magnitude and determinants of FDI with a special focus on the euro effect from a third-country

\footnotetext{
${ }^{1}$ As reported in Carril-Caccia and Pavlova (2018) the estimated increase in FDI due to the EU membership ranges between 28 and 83 percentage points, while the incremental effect of euro area membership ranges between 21 and 44 percentage points. However, these studies consider different periods and different sets of countries, so they are not fully comparable. See, i.e. Baldwin et al. (2008), Neary (2009) and Stojkov and Warin (2018).

${ }^{2}$ See also Coeurdacier et al. (2018).
} 
perspective, namely, the FDI coming from the United States (US), the most prominent investor in the EU from a historical standpoint. The analysis of the factors driving FDI into the EU from third countries, and especially from the US, although scarcely studied, is a major topical issue for several reasons. First, the EU is the main destination for FDI in the world: FDI stocks held by third country investors in the EU amounted to €6,295 billion at the end of 2017, providing Europeans with 16 million direct jobs (European Comission, 2019). Second, from an economic policy point of view, apart from the well-established advantages brought by FDI in terms of convergence and technological diffusion promoting growth and employment, it also represents a key source of external financing with clear macroeconomic consequences. As countries in the euro-area periphery are seeking to redress imbalances and reduce their liabilities in a period of low growth prospects, FDI is becoming increasingly important as a potential driver of growth. This is because it is a non-debt-creating liability, but also because it is typically more productive than internal investments. ${ }^{3}$ Third, as the largest share of FDI into EU Member States is from EU firms (intra-EU), and this is also the component that has seen the greatest decline since the end of 2007, the analysis of inward FDI into the EU from third countries is gaining momentum. Finally, with the entry into force of the Lisbon Treaty in December 2009, the EU's exclusive competence over the common commercial policy has been extended to cover FDI as well now. The EU has one of the world's most open investment regimes, as acknowledged by the OECD in its IP/19/2088 investment restrictiveness index. In terms of countries of origin, the "traditional" main investors in the EU are still advanced economies such as the US, Switzerland, Norway, Canada, Australia and Japan. They remain well ahead and still control more than 80 percent of all foreign-owned assets. In 2016, US and Canadian investors accounted by far for the largest share of foreign investors in terms of assets controlled (61.8\%). They started investing since the creation of the EU and have kept their acquisition rates constant over time.

Historically, the US and the EU (and its predecessors) have extensive trade and investment ties that have evolved since the Second World War as EU members have grown in parallel with the upsurge of global supply chains and increasing cross-border investment. According to Kim (2004) most of US FDI flows in Europe in the early 1960s were characterized as defensive import-substituting investments to supply local markets (HFDI). However, at the end of the 1980s, 85 percent of the market for US goods and services in the EU were

\footnotetext{
${ }^{3}$ See Helpman (2006).
} 
supplied by the US affiliates, while exports from the US had just a residual role. As a result, the economic integration processes in Europe have turned the type of US FDI into "rationalizing" motive investments (VFDI) and offensive export substituting investments (HFDI). The former reduce the number of locations to supply all European markets and the latter are led by strategic asset seeking. In 2018, the largest destinations in the EU for US investment were the Netherlands ( $\$ 883$ billion), the UK ( $\$ 758$ billion), Luxembourg ( $\$ 714$ billion), and Ireland ( $\$ 442$ billion).

As regards the empirical literature on FDI stemming from countries outside the monetary union, Baldwin et al. (2008), Neary (2009) and Sondermann and Vansteenkiste (2019) argue that the greater integration of the Eurozone market might make it more attractive to have a production platform inside the Eurozone. Empirically, this is confirmed by Petroulas (2007) who finds also a pro-FDI euro effect from investor countries outside the monetary union; however, this effect was found to be smaller than for intra-euro area FDI. Straathof et al. (2008), who analyze the internal market effect on trade and FDI using bilateral data of FDI stocks for 30 OECD countries from 1981 to 2005 in a gravity model find that EU countries attract $14 \%$ more FDI from EU-outsiders. More recently, two other additional factors may have interacted with the possible euro effect affecting inward FDI coming from third countries. First, the effects of the Great Recession. Indeed, the EU's weight in global inward FDI decreased after 2007, but has rebounded somewhat since 2015. On average, between 2000 and 2007, EU countries attracted 43.1\% of the world's FDI, while in the period 2008-16 the EU attracted, on average, only a $26.7 \%$. However, this drop in inward FDI into the EU owing to the crisis has been more marked in non-euro area EU countries and from 2015 the EU has been witnessing a surge in new investors from emerging economies, mainly China, Singapore and Brazil. In detriment of more classic investing countries, as the US, a second factor that may affect inward FDI from the US is the Brexit issue; although the impact of Brexit is uncertain, most studies have estimated an aggregate reduction in FDI into the UK of between 12\% and 28\% (See Campos, 2019; Campos et al., 2019) 4 . This FDI diversion from both, EU countries and the rest of the world, can be due to the future increasing cost of accessing the EU Single Market from the UK, making the country less attractive for foreign investors.

In our research, we are interested in studying the determinants of US FDI in Europe and,

\footnotetext{
${ }^{4}$ See, also, Dhingra et al. (2016), Bruno et al. (2016) or Treasury (2016).
} 
in particular, the role of the euro and the process of monetary integration. But, in order to obtain robust statistical and economic results, we also consider the rest of the countries that receive American FDI around the world. In particular, our sample contains the stock of US outward FDI (OFDI) in 56 countries from 1985 to 2017, which represents the 67.2\% of total US FDI stock in $2017^{5}$. We also consider EU and EA countries separately. Furthermore, to the best of our knowledge, no previous empirical study has analyzed whether and how the introduction of the euro has affected the US FDI patterns across different EA member groups, i.e. the locational choice between core and periphery of the EA. In our case, we distinguish between both groups not only in terms of geographical criteria, but also of economic similarities. Indeed, Bayoumi and Eichengreen (1993), Zhang and Artis (2001) and Konstantakopoulou and Tsionas (2011) among others, found that this classification could be based on business cycles synchronicity and common economic shocks. In the core we include Germany and its immediate neighbouring Eurozone countries whereas in the periphery are those EA countries which are farther from the centre, that is, those of Northern as well as the Southern Europe. Mostly in the latter, labour costs and GDP per capita are lower. Therefore, although both HFDI and VFDI motivations are possible in these two groups, we expect that in the core HFDI predominates, whereas in the periphery VFDI prevail.

Moreover, we divert from previous studies by introducing several novelties in our research. First, to analyse the US OFDI determinants and the euro membership effect, instead of just focusing on a specific regression model and on an ad hoc gravity setting, we consider a wide set of 63 FDI potential determinants. Second, to select and assess the relative importance of the incumbent covariates overtime we apply a Bayesian Model Averaging (BMA) analysis. Bayesian inference offers the tools to attach probabilities to the different possible models. Raftery (1995) showed that when there are many candidate independent variables, standard model selection criteria based on p-values can be misleading. The uncertainty surrounding FDI modelling makes the BMA methodology especially suited to discriminate among the large set of candidate regressors that has been posited as possible FDI determinants by different theories. Chakrabarti (2001) was the first to put forward this uncertainty in FDI studies using Extreme Bound Analysis. More recently, Blonigen and Piger (2014) and Eicher et al. (2012) use a BMA approach to account for model uncertainty in FDI. A third distinctive feature of our study is that we also introduce a deeper measure to review the

\footnotetext{
${ }^{5}$ See Bureau of Economic analysis (BEA) statistics.
} 
effect of the common currency on US OFDI instead of using a "naive" euro dummy which simply takes the value 1 as of the euro adoption, and 0 otherwise. According to Sondermann and Vansteenkiste (2019), the launching of the euro was not a discrete event, but rather an on-going process which started several years prior to the introduction of the new currency and continued also thereafter. Consequently, we construct a variable euro that captures the whole process of monetary integration in Europe, that is, the different stages prior to the adoption of the common currency. Finally, to find out if the adoption of the euro has changed the drivers of US FDI, we use our dummy euro and its interaction with other variables (see table 2 ).

The main findings suggest that many variables considered by the previous FDI literature are not found to be robust determinants using BMA techniques. Moreover, US OFDI is explained by both horizontal and vertical FDI motives in all country groups. However, HFDI strategies predominate in EA core countries, whereas VFDI prevails in the EA periphery. As for the euro effect, the launching of the common currency seems to have played an important role encouraging US FDI, being an important element in the integration of EA periphery to the core. In addition, our results indicate that the adoption of the euro has favoured VFDI to the detriment of market-seeking or HFDI.

The reminder of the paper is organized as follows: in Section 2 we briefly review the main theoretical approaches to FDI determination, with an emphasis in the formulated hypotheses and their differences; Section 3 presents a summary of the BMA methodology, while Section 4 describes our database and discusses the estimated results. Finally, Section 5 concludes.

\section{The underlying literature}

\subsection{Types and decisions of foreign direct investment}

The analysis of FDI determinants is complex because of the diversity of multinational companies (MNCs) and different reasons for investing abroad. However, the literature has traditionally focused on two forms of FDI , namely, HFDI, motivated by market access, and VFDI, encouraged by comparative advantage.

In the theory of HFDI, a firm invests abroad by replicating a part of its activities or production processes in another country so as to avoid transportation costs, tariffs and other types 
of trade costs. This strategy is referred to as "market access motive" and was introduced by Markusen (1984) and Markusen and Venables (1999, 2000). In HFDI models, exports and FDI are substitutes, and the decision to serve a market via exports or setting up an affiliate company abroad constitutes a proximity-concentration trade-off, that is, to concentrate the production in a local firm and serve the foreign market via exports, or becoming close to the foreign market through a subsidiary firm. The key hypothesis concerning transportation cost is that FDI increases when transportation and trade costs are substantially high.

On the other hand, firms engage in VFDI when they fragment their production process across countries. The main reason for such disaggregation is the cost considerations arising from countries' factor cost difference. Firms are encouraged to fragment production and locate a production stage in a country where the factor used intensively in that stage is abundant. This strategy is known to as the "comparative advantage motive" and was introduced by Helpman (1984) and Helpman and Krugman (1985). The effect of trade and transportation costs is negative in VFDI, in contrast to HFDI, where such effect is positive.

More recent strands of the literature suggest other foreign investment strategies, alternatives to HFDI and VFDI, such as the knowledge-capital model (Markusen et al., 1996; Carr et al., 2001; Markusen and Maskus, 2002). Overall, under the knowledge-capital model, similarities in market size, factor endowments and transport costs were determinants of HFDI, while differences in relative factor endowments determined VFDI. The knowledgecapital model has recently been extended to explain other forms of FDI such as exportplatform FDI (Ekholm et al., 2007; Bergstrand and Egger, 2007) which is used to serve the neighboring markets of the host country. To sum up, while recent Eaton-Kortum (Ricardian) type models have been extended to motivate gravity equations for multinational production, theoretical foundations for FDI per se are limited primarily to Bergstrand and Egger (2007). ${ }^{6}$

The eclectic $\mathrm{OLI}^{7}$ paradigm has also a crucial importance in the literature of FDI decisions. This theory was proposed by John H Dunning in $1980^{\circ}$, and until nowadays has remained the dominant analytical framework for accommodating a variety of operationally testable economic theories of the determinants of FDI and the foreign activities of MNCs.

\footnotetext{
${ }^{6}$ While Markusen and Maskus (2002) knowledge-capital model is about foreign affiliate sales (FAS), Bergstrand and Egger (2007) is about both, FAS and proper FDI.

${ }^{7}$ Ownership, Location and Internalization.

${ }^{8}$ See Dunning (1980).
} 
It maintains that FDI decisions of MNCs are determined by the interaction of three sets of interdependent variables: Ownership, location and internalization advantages. The eclectic paradigm reflects the economic and political features of the country or region of the investing firms and those of destination countries, as well as the industry and the characteristics of individual investing firms, including their objectives and strategies (Dunning, 2000). This contextual framework leads to four types of FDI: Market-seeking FDI or HFDI, resource-seeking FDI or VFDI, efficiency-seeking FDI and strategic asset-seeking FDI: Market-seeking motives try to satisfy a particular foreign market, or set of foreign markets; resource-seeking FDI is designed to gain access to natural resources, agricultural products or unskilled labor; efficiency-seeking FDI promotes a more efficient division of labor or specialization of an existing portfolio of foreign and domestic assets by MNCs; and strategic-asset seeking FDI protects or augments the existing ownership specific advantages of the investing firms and/or to reduce those of their competitors by acquiring specific technological competence or qualified human capital not available at home.

In order to discriminate between competing theoretical approaches of FDI determinants, the estimation of gravity equation has been successfully applied in the empirical literature. In this case, as in gravity models applied to trade flows, the gravity approach to FDI describes the volume of bilateral FDI between two countries as positively related to their economic sizes and negatively to the distance between them. During the last decade, some of the literature on FDI tried to generalize the use of the gravity approach to analyze FDI patterns (Brainard, 1997; Eaton and Tamura, 1994). Nonetheless, there was a lack of theoretical foundation for the gravity equations for FDI. Since Bergstrand and Egger (2007) such a theoretical foundation does exist. They extend the $2 \times 2 \times 2$ knowledge-capital model in Markusen and Maskus (2002), by adding an extra factor and country, and derive a specification for the FDI gravity equation that explains its empirical fit to the data. This paper, together with the one by Head and Ries (2008), are considered the only two formal general equilibrium theories for FDI. Subsequently, more research followed and the theoretical justification of the gravity model for FDI is not longer questioned. Kleinert and Toubal (2010) illustrate how an aggregate FDI equation can be derived from different theoretical models. In particular, we adopt here the Kleinert and Toubal (2010) horizontal model where firms can serve the foreign market $j$ either by producing abroad or by exporting. The gravity equation estimated by Kleinert and Toubal (2010) is as follows: 


$$
A S_{i j}=s_{i}\left(\tau D_{i j}^{\eta^{1}}\right)^{(1-\sigma)(1-\epsilon)} m_{j}
$$

where $A S_{i j}$ are aggregate sales of foreign affiliates from firm $i$ in $j ; s_{i}$ and $m_{j}$ denote home and host country's market capacity, respectively, and $\tau D_{i j}^{\eta^{1}}$ stands for geographical distance between $i$ and $j$ where $\tau$ represents the unit distance costs and $\eta_{1}>0$.

Equation 1 can be log-linearized as

$$
\ln \left(A S_{i j}\right)=\alpha_{1}+\zeta_{1} \ln \left(s_{i}\right)-\beta_{1} \ln \left(D_{i j}\right)+\xi_{i} \ln \left(m_{j}\right)
$$

This type of expression is the one commonly used in the gravity models for FDI as well. Next, we will see that most of the postulated covariates can be related either with some measurement of economic distance or with market size.

\subsection{Choosing FDI determinants using Bayesian techniques: a short literature review}

Most of the factors mentioned above are related to location determinants. Many empirical studies have adopted a gravity equation approach from the international trade literature and examined the patterns of FDI as a function of country characteristics such as market size, distance, factor endowment, transportation cost, tariffs, corporate taxes, natural resources, institutional quality and exchange rate among others ${ }^{9}$. Consequently, a wide range of different variables has been employed in the literature.

However, there is little consensus on which ones are postulated to be potential FDI determinants. The main reason for this lack of consensus is that previous research has generally focused on regression models involving specific sets of variables determined by the researcher and the particular theoretical framework for FDI they chose to analyze. By conditioning on a particular regression model specification, this practice ignores uncertainty regarding the model specification itself, which might have dramatic consequences on inference. Particularly, inference regarding the effects of the covariates considered in a particular specification can depend critically on the rest of the included or even omitted variables. Next, we summarize the most recent evidence and techniques applied on variable selection in the case of FDI determination.

\footnotetext{
${ }^{9}$ See, for example, Anderson and Wincoop (2003), Chaney (2008), Disdier and Head (2008), Head and Mayer (2014) for surveys of the trade gravity literature.
} 
Following a frequentist approach, Chakrabarti (2001) used Extreme Bound Analysis (EBA) to determine which explanatory variables are "robust" and which are "fragile" FDI determinants to small changes in the conditioning information set. The dependent variable employed is per capita FDI inflows. In a cross-section sample of 135 countries for 1994 he finds that market size, measured as GDP per capita, has a strong explanatory power to explain FDI in the host country.

A methodology that was proposed earlier, known as BMA, was found to be a better method to account for model uncertainty as part of the estimation procedure (see, for example Raftery, 1995). According to Berger and Sellke (1987), conventional sensitivity analyses overstate the significance and the width of confidence intervals when model uncertainty is not accounted for. If this is the case, whether a statistically significant FDI determinant is relevant when alternative specifications are considered remains ambiguous. The BMA methodology can be applied to examine the large set of variables that have been proposed as FDI determinants by alternative FDI theories. ${ }^{10}$ A difficulty commonly found in this type of analysis is that even the most comprehensive FDI datasets contain large sections of missing data, that happens when the researcher wants to include as many countries as possible. In our case, this problem does not apply, as we consider only the countries with complete information. ${ }^{11}$

More directly related to our research is the contribution of Blonigen and Piger (2014), that apply Bayesian statistical techniques to obtain the most relevant FDI determinants for a group of OECD countries, as well as for the world economy in 2000. In contrast to Eicher et al. (2012), and Jordan and Lenkoski (2018), Blonigen and Piger (2014) use both FDI flows

\footnotetext{
${ }^{10}$ Obviously, Bayesian statistical techniques have not only been applied to FDI, but also to other fields of economics. These are the cases of export market shares (Benkovskis et al., 2019), the current account balance (Desbordes et al., 2018), the relationship between energy consumption and economic growth (Camarero et al., 2015) and growth models (Fernández et al., 2001). In the present research, we apply a robust probabilistic approach to select the explanatory variables from a large set of potential candidates. For that objective, we use the R-package BayesVarSel (García-Donato and Forte, 2015), and apply Bayesian Variable Selection techniques for linear regression models using Gibbs sampling.

${ }^{11}$ If the missing data are unevenly distributed,they may create a selection bias problem that can question the accuracy of the coefficient estimates. This problem is, notwithstanding, relevant in this literature and has been solved using different approaches. For example, Eicher et al. (2012) who introduced Heckit BMA. They use a sample of 46 countries (25 OECD countries) from 1988 to 2000, and FDI flows as the dependent variable. The results show only mixed support for horizontal or export platform FDI theories, whereas the evidence of vertical FDI was quite weak. Jordan and Lenkoski (2018) use a Tobit Bayesian Model Averaging (TBMA) technique to improve the estimation of the inclusion probabilities of Eicher et al. (2012) and develop a full Bayesian model. Such method gives support for roughly the same determinants as the Heckit BMA when modeling the magnitude of FDI flows.
} 
and stocks. They found that the variables with consistently high inclusion probabilities include traditional gravity variables such as cultural and distance factors, relative labour endowments and trade agreements.

Antonakakis and Tondl (2015) employ the same methodology to examine the determinants of the outward FDI stock from OECD investors to 129 developing countries over the period 1995-2008. Their results suggest that no single theory governs the decision of FDI from OECD regions to developing countries but a combination of theories. In particular, OECD investors tend to choose countries with whom they have established intensive trade relations and offer qualified labour force. Other potential determinants are low wages, attractive tax rates and resource abundance.

\section{Econometric methodology}

\subsection{Bayesian methods for model selection}

As discussed above, two important challenges to the study of FDI determinants are, first, the large amount of potential explanatory variables and, second, the heterogeneity of model specifications proposed in the theoretical and empirical literature. Even if the potential effect of these variables on FDI is known and derived from the theory, their ultimate presence in the model is unknown. This type of situation defines a particular model selection problem known as variable selection, formally introduced in this section.

In model selection, the true statistical model is unknown and this uncertainty is explicitly considered. The Bayesian approach to model selection has a number of appealing theoretical properties described in Berger and Pericchi (2001). The final product of such approach is the posterior distribution over the model space; a probability mass function that assigns to each model its probability conditional on the data observed. The attractiveness of this function lies in its easiness for the evaluation of any question relevant to the analyst in probabilistic terms. Despite its appeal, the implementation of Bayesian variable selection presents some difficulties. These obstacles are associated with the assignment of the prior distribution and the necessity of approximating the posterior distribution with a large number of potential models. The improvement in computing capacity and the implementation of the algorithms in widely used software have extended its academic use. In our case, we use the R package BayesVarSel (García-Donato and Forte, 2015), which solves 
the implementation problems in a user-friendly interface.

\subsection{The variable selection problem}

Concerning variable selection, each entertained model corresponds to a specific subset of a group of (e.g., $k$ ) initially considered potential explanatory covariates. Therefore, the model space $\mathcal{M}$ has $2^{k}$ potential models and each competing model $M_{j}$ for $j=0, \ldots, 2^{k}$ relates the response variable to a subset of $k_{j}$ covariates, such as:

$$
y_{i t}=\alpha_{j}+X_{j, i t} \beta_{j}+\gamma_{j, i}+\epsilon_{j, i t} \quad \epsilon_{j, i t} \sim \mathcal{N}_{n}\left(0, \sigma^{2} I\right),
$$

where $i=1, \ldots, N$ is the number of countries; $t=1, \ldots T$ is the number of periods of time; $\alpha_{j}$ is the constant term; $y_{i t}$ is the $n$ dimensional vector of observations for the response variable, the US OFDI stock in the host country; $X_{j, i t}$ is the $n x k_{j}$ design matrix of FDI determinants; $\epsilon_{j, i t}$ a white noise error with zero mean and constant variance; and $\gamma_{j, i}$ is an unobservable time-invariant country heterogeneity component. Such component may introduce a bias in the results. In order to remove it, we are going to employ fixed effects. Within the BMA methodology, as proposed by Moral-Benito (2013), it consists on subtracting the country mean for every observation using the within transformation. Considering the $\operatorname{model} M_{j}\left(j=1, \ldots, 2^{k}\right)$ :

$$
\begin{gathered}
\left(y_{i t}-\bar{y}_{i}\right)=\alpha_{j}+\left(X_{j, i t}-\bar{X}_{j, i}\right) \beta_{j}+\left(\gamma_{j, i}-\bar{\gamma}_{j, i}\right)+\left(\epsilon_{j, i t}-\bar{\epsilon}_{j, i}\right) . \\
\ddot{y}_{i t}=\alpha_{j}+\ddot{X}_{j, i t} \beta_{j}+\ddot{\epsilon}_{j, i t} \quad \ddot{\epsilon}_{j, i t} \sim \mathcal{N}_{n}\left(0, \sigma^{2} I\right) .
\end{gathered}
$$

Where $\bar{X}_{j, i}=\frac{1}{T} \sum_{t=1}^{T} X_{j, i t} ; \bar{\epsilon}_{j, i}=\frac{1}{T} \sum_{t=1}^{T} \epsilon_{j, i t}$; and $\alpha_{j}$ is the constant term. Moreover, $\ddot{y}_{i t}$ is the $n$ dimensional vector of observations for the response variable, the US FDI stock in the host country; $\ddot{X}_{j, i t}$ is the $n x k_{j}$ design matrix of host country FDI determinants; and $\ddot{\epsilon}_{j, i t}$ a white noise error with zero mean and constant variance again, but this time in terms of mean deviations.

Assuming that one of the models in $\mathcal{M}$ is the true model, the posterior probability of any model is:

$$
P\left(M_{j}^{*} \mid y\right)=\frac{m_{j}^{*}(y) P\left(M_{j}^{*}\right)}{\sum_{j} m_{j}(y) P\left(M_{j}\right)},
$$


where $P\left(M_{j}\right)$ is the prior probability of $M_{j}$ and $m_{j}$ is the integrated likelihood with respect to the prior distribution for the parameters $\pi_{j}$ :

$$
m_{j}(y)=\int f_{j}\left(y \mid \beta_{j}, \alpha_{j}, \sigma\right) \pi_{j}\left(\beta_{j}, \alpha_{j}, \sigma^{2}\right) d \beta_{j} d \alpha_{j} d \sigma^{2}
$$

also called the (prior) marginal likelihood.

\subsection{Prior specification}

The two inputs that are needed to obtain the posterior distributions are $\pi_{j}$ and $P\left(M_{j}\right)$ : the $2^{k}$ prior distributions for the parameters within each model and the prior distributions over the model space, respectively.

The prior distributions $\pi_{j}$ can be expressed as:

$$
\pi_{j}\left(\beta_{j}, \alpha_{j}, \sigma^{2}\right)=\pi_{j}\left(\beta_{j} \mid \alpha_{j}, \sigma^{2}\right) \pi_{j}\left(\alpha_{j} \mid \sigma^{2}\right)
$$

In our work, we implement the prior distribution for the parameters proposed by Bayarri et al. (2012), which fulfil different criteria that should be taken into account to drive a variable selection problem and provide a reliable theoretical result at relatively small computational cost. This prior, known as the Robust prior, is:

$$
\pi_{j}^{R}\left(\alpha_{j}, \beta_{j}, \sigma\right)=\pi\left(\alpha_{j}, \sigma\right) x \pi_{j}^{R}\left(\beta_{j} \mid \alpha_{j}, \sigma\right)=\sigma^{-1} \times \int_{0}^{\infty} k_{i}\left(\beta_{i} \mid 0, g \Sigma_{i}\right) p_{i}^{R}(g) d g,
$$

where $\Sigma_{i}=\operatorname{Cov}\left(\hat{\beta}_{i}\right)=\sigma^{2}\left(V_{i}^{t} V_{i}\right)^{-1}$ is the covariance of the maximum likelihood estimator of $\beta_{i}$ with

$$
V_{i}=\left(I_{n}-X_{0}\left(X_{0}^{t} X_{0}\right)^{-1} X_{0}^{t}\right) X_{i}, \quad X_{0}=\left(1_{n}, y_{-1}\right)
$$

In equation 9, the hyperparameter $g$ determines the strength of the researcher's prior belief that the coefficients are zero. A small (large) value of $g$ indicates that the researcher is very certain (uncertain) that the coefficients are zero. The choice of a fixed value of $g$ could critically affect posterior inference and predictive accuracy. According to Liang et al. (2008) and Feldkircher and Zeugner (2009), posterior results depend substantially on the researcher's prior choice under a fixed g-prior, ignoring the true underlying data generating process. Both studies highlight that flexible $g$-priors, those which allow to update prior 
beliefs according to data quality, adapt better to the information content in the data.

In our research, we employ the flexible- $g$ prior proposed by Bayarri et al. (2012) within the Robust prior:

$$
p_{j}^{R}(g)=\frac{1}{2} \sqrt{\frac{1+n}{k_{j}+k_{0}}}(g+1)^{-3 / 2}, g>\frac{1+n}{k_{j}+k_{0}}-1,
$$

Above, $k_{0}$ denotes the number of fixed covariates, which in our case is $k_{0}=1$, the constant term.

With respect the prior over the model space $\mathcal{M}$, it can be approximated as:

$$
P\left(M_{j} \mid \theta\right)=\theta^{k_{j}}(1-\theta)^{k-k_{j}}
$$

where $k_{j}$ is the number of covariates in $M_{j}$, and the hyperparameter $\theta \in(0,1)$ has the interpretation of the common probability that a given variable is independently included.

Most of the previous literature has chosen $\theta$ as fixed, $\theta=1 / 2$, which assigns equal prior probability to each model $\left(P\left(M_{j}\right)=1 / 2^{k}\right)$; or random, $\theta \sim \operatorname{Unif}(0,1)$, giving equal probability to each possible number of covariates or model size (Scott and Berger, 2010). According to Forte et al. (2018), using a fixed value of $\theta$ performs poorly in controlling for multiplicity (the occurrence of spurious explanatory variables as a consequence of performing a large number of tests). For these reasons, in our research we make use of random $\theta \sim \operatorname{Unif}(0,1)$ for the prior distribution over the model space.

\subsection{Summaries of the posterior distribution and model averaged inference}

When $k$ is moderate to large, posterior probabilities of individual models can be very small. A useful summary is the posterior inclusion probabilities (PIPs) of every covariate, defined as:

$$
P\left(x_{r} \mid y\right)=\sum_{x_{r} \in M_{j}} P\left(M_{j} \mid y\right), i=1, \ldots, k
$$

These should be interpreted as the importance of each variable for explaining the response variable. According to Raftery (1995), evidence for a regressor with a posterior inclusion probability from 0.50 to 0.75 is called weak, from 0.75 to 0.95 positive, from 0.95 to 0.99 strong, and $>0.99$ very strong. 
The posterior distribution easily allows for obtaining model averaged estimates of any quantity of interest $\Delta$ (assuming it has the same meaning across all models). If $\Delta$ refers to the regression coefficients $\left(\beta_{r}\right)$ :

$$
P\left(\beta_{r} \mid Y\right)=\sum_{M_{j}} P\left(\beta_{r} \mid M_{j}, y\right) P\left(M_{j} \mid y\right)
$$

In this case, the model averaged estimates should be used and interpreted with caution because the "same" parameter may have a different meaning in different models (Berger and Pericchi (2001)).

\subsection{Sampling method for posterior estimation}

Another important question within the Bayesian techniques is the number of models in $\mathcal{M}\left(2^{k}\right)$. If $k$ is small (say, $k$ in the twenties at most), exhaustive enumeration is possible but if $k$ is larger, heuristic methods need to be implemented. According to García-Donato and Martínez-Beneito (2013), sampling methods with frequency-based estimators outperform searching methods with renormalized estimators. The searching procedure of this last group could bias the estimation. Within the sampling methods with frequency-based estimators, highlights the Gibbs sampling of George and McCulloch (1997). This method is a Markov Chain Monte Carlo (MCMC) technique which generates posterior samples by sweeping through each variable to sample from its conditional distribution with the remaining variables fixed to their current values. In our work, we are going to apply this sampling method.

\section{Data and empirical results}

\subsection{Data}

In this paper, we analyze the potential determinants of US OFDI stock for the period 19852017, with special emphasis in the euro effect. To this aim, we have considered 63 different variables available for the 56 FDI destinations or host countries and the time range analysed in our sample. These variables have been selected in accordance to previous theoretical and/or empirical literature on the determinants of FDI. We also analyse whether these determinants differ when we consider all the host countries in the sample and when we 
focus on different groupings, namely the EU, EA and core and peripheral EA countries. As we estimate through fixed effects, time-invariant variables are not included ${ }^{12}$. Concerning the effect of the common currency, we create a dummy variable based on the methodology of Baier and Bergstrand (2007) in their Economic Integration Agreement Database (EIA), taking different values following the process of monetary integration to the adoption of the euro. In particular, we distinguish three levels in the process of monetary integration in Europe: a value of 1 is given if the host country is outside the ERM but its currency is pegged to either the DMark/the ECU/or the Euro; 2 if its currency is pegged to the ECU or the euro via the ERM; 3 if its currency is the euro, and 0 otherwise. Moreover, we interact this variable with those classified in the groups "market size", "labour market and skills", "trade and international openness" and "institutional quality". These groups of variables have been the most frequently employed in previous FDI literature and suitable to assess whether there has been a change in the drivers of US FDI with the creation of the euro. In Table 1 we enumerate the countries included in the different groups considered in our analysis. Table 2 contains the candidate variables grouped by the different criteria (mostly countries' characteristics) commonly considered in the literature. We also describe how they have been defined, their source and report previous studies that have also used these countries'characteristics. To ease the discussion of the empirical results, we will follow the same ordering in the next section.

\subsection{Empirical results}

The results for the different country-groups analyzed are presented in table 3 . The posterior inclusion probabilities and the posterior means of the different samples and estimations have been obtained using the Gibbs sampling from the best 100000 models. This number of iterations guarantees PIPs convergence, as they stabilize long before, at around 20000 iterations, which is the maximum that the R-function GibbsBvs allows in the plots (see Appendix A, Figures 1 to 5). Following the same order as in Table 2, the variables are grouped according to country characteristics. We will consider that a covariate is potentially relevant when its PIP is higher than 0.5, as suggested by Raftery (1995), or is close to this threshold and is at least in one of the best 10 models. These cases are marked in bold in the table. In addition, we have also included descriptive graphs of the posterior inclusion probabilities

\footnotetext{
${ }^{12}$ For more information about fixed effects estimation in panel data, see Fernández-Val and Weidner (2016), Fernández-Val and Weidner (2018) and Weidner and Zylkin (2019).
} 
in Appendix B. It is important to highlight that the posterior means cannot be considered parameters, as they are averages of the coefficients of the best 100000 models taking into account their posterior probabilities (see equation 14). However, they are still illustrative as they provide the mean effect of each covariate on US OFDI stock. Finally, even if some interactions have high PIP, we only interpret them if both variables in such interaction are relevant individually.

As the main focus of this paper is to study the role of the euro on US OFDI, the first group of variables that we discuss are those under the heading Economic and monetary integration. Our variable euro is a relevant determinant and has a positive posterior mean for the whole sample, as well as for EU and EA countries groups. Moreover, we obtain interesting results when we divide our EA sample into core and peripheral countries. For the core countries, the euro is not selected, probably because (with the exception of Austria that joined the EU and the ERM in 1995) all of them were old members of the system since 1979 and even before that ${ }^{13}$ and their currencies have remained stable during the whole period considered. Instead, we find that what really has affected US OFDI in these countries is being members of the EU, as the variable economic integration is the one relevant for this group ${ }^{14}$. On the other hand, the adoption of the common currency is a potential determinant with a positive posterior mean for the EA peripheral countries. This result, together with the irrelevance of the euro for the core countries, implies that participating in the process of monetary integration and stabilizing exchange rates has attracted FDI from the US into the peripheral countries. Therefore, there are two phases of American FDI into the European continent, more recent for the periphery, whereas earlier stages of economic integration drove US MNCs towards the core. Indeed, the dummy economic integration, with the exception of the whole sample, is a robust US OFDI determinant for the rest of groups, that is, for EU countries.

The second group consist of market size and population measures. At first sight, it is remarkable that for the whole sample we obtain many variables with high PIP. ${ }^{15}$ When we study more homogeneous and small samples, the number of potential covariates notably

\footnotetext{
${ }^{13}$ Germany, the Netherlands, France and Belgium not only founded the ERM in 1979 but were also members of the European Snake since 1972.

${ }^{14}$ This dummy captures the different levels of integration, from trade agreements to a common market

${ }^{15}$ This is, by far, the largest group of countries we analyze (a total of 56), and even if we have removed the unobservable time-invariant country heterogeneity from our estimation (see subsection 3.2), they remain very diverse. A large sample increases the power of the BMA analysis, being able to detect very small size effects, and then, a large number of variables can be considered relevant.
} 
decreases.

Concerning the selected variables, the real GDP of the host country is relevant for all the groups, with a posterior mean positive and between 0.6 and 2.9. The sum of host and US real GDP also appears in the larger group and the EU countries, with a positive sign as well and around 1.5, consistent in both cases with market-seeking FDI or HFDI. Similar results where found by Carr et al. (2001), Markusen and Maskus (2002), Blonigen et al. (2003), Bergstrand and Egger (2007) and Chiappini (2014) among others. The urban population of the host country is also relevant for the whole group, core countries and periphery. ${ }^{16}$ Regarding the interactions with the euro included in this group, the joint effect with the real GDP of the host country is a potential OFDI determinant for all the groups with the exception of the core and a negative mean effect. On the other hand, the interaction eurourban population of the host is only relevant for the large group, with a positive sign.

Three covariates (the difference between US and host real GDP, real GDP growth and real market potential) are only relevant in the larger group. The positive sign of the first might capture the relative importance of small countries as FDI destinations in comparison with other large countries considered in this group, such as Japan and China. Indeed, once we consider more homogeneous groups, where only European countries are included, this variable is not longer relevant. Similarly, the real GDP growth of the host country is only a potential FDI determinant for the whole sample with a negative sign. Concerning the third variable, real market potential, we have calculated it following Blonigen et al. (2007) to capture spatial interdependence in FDI location decisions. We find a negative sign for the whole sample. This effect is unexpected, but may represent a substitutability pattern between FDI in the host country and neighbouring regions, as an increase in their GDP reduces FDI in the host country. A related variable, the spatial lag of US FDI ${ }^{17}$ has a positive posterior mean for the whole sample. In this case, the variable is relevant for the EU and the core as well, the latter with a negative sign. Comparing market potential and spatial lag the results seem contradictory for the larger sample. However, this situation changes when we study the rest of the groups. The absence of the covariate market potential and the relevance and positive sign of the spatial lag US FDI for EU countries point at the importance of agglomeration forces and of having suppliers in neighbouring regions, strategy

\footnotetext{
${ }^{16}$ Its posterior mean is positive for the core (HFDI) and negative for the other two groups, that would imply resource seeking FDI or VFDI.

${ }^{17}$ Defined as the sum of US FDI in the host's neighboring countries wieighted by the distances (see Table 2 for more details).
} 
consistent with vertical specialization. On the other hand, the negative posterior mean of this last variable for the core countries means that US MNCs evaluate all neighbouring markets, which in this case are mostly EA peripheral countries, to find the one that is the lowest-cost provider of the activity, motivation in line with VFDI. Lastly, the non relevance of any of these two variables for EA countries,including the periphery, would imply HFDI. Finally, the old dependency ratio of the host country is a robust determinant for the EA countries. Its positive posterior mean could indicate that advanced economies have more developed credit markets and a wider social security coverage (Coeurdacier et al., 2018).

As for the labour market variables ${ }^{18}$, the skill level, HCI and labour compensation of the host country display a negative posterior mean. Moreover, except for the whole group, the population density of the host country has a positive sign ${ }^{19}$. Therefore, US MNCs have been looking for unskilled, cheap and abundant labour probably with the progressive fragmentation of their production processes, strategy consistent with VFDI. This motivation is reinforced when we analyze labour endowment dissimilarities. Education and the difference in skill level between the US and the host country are, as well, robust FDI determinants with a positive sign for the whole and EU samples. These groups of countries contain the largest proportion of emerging and developing $\operatorname{countries}^{20}$, whose labour endowments in terms of education and skill levels are notably lower in comparison with the US. These results are compatible with the knowledge-capital model of Carr et al. (2001). Concerning the euro effect, its interaction with population density it is found to be relevant for all the samples with the exception of the core countries, with a positive sign. In addition, its interaction with the skill level of the host country is also a potential FDI determinant for EA countries. Its posterior mean is positive. Therefore, with the introduction of the euro, US MNCs have been looking for skilled and abundant workforce in EA countries. Because abundant labour endowment represents lower labour costs, this result would still be consistent with VFDI strategies. As for the US MNCs shift from unskilled to skilled labour demand, there are several papers that can explain this change. According to Noorbakhsh et al. (2001),

\footnotetext{
${ }^{18}$ See Table 2 for the complete list, definition and sources of candidates.

${ }^{19}$ The reason explaining the negative sign of population density is that it could attract a higher concentration of firms looking for abundant and cheaper labour. Consequently, the competition effect could offset the positive spillovers arising from a common pool of resources, deterring the entry of new firms. For more information about competition forces and FDI location, see Crozet et al. (2004).

${ }^{20}$ In the whole sample an important proportion of countries are from Central and Latin America, East Asia, East Europe and Africa. Moreover, the EU group contains the available Central and Eastern European countries.
} 
the importance of human capital has increased as MNCs need local skills together with complementary factors of production or business related services such as the access to local finance. Furthermore, Machin (2001) and McIntosh (2002) agree on that the increasing importance of technology in the production of goods and services has shifted the demand requirements of employers to hire more qualified, replacing many low-skilled jobs. This trend has deepened during the last two decades, especially if we take into account that the percentage of population with at least some secondary education has notably increased for EA countries during this period (see UNDP statistics at http://hdr. undp.org/en/data). Moreover, beyond labour cost considerations, skilled workers can also be a VFDI attractiveness. Alfaro and Charlton (2009) found that most VFDI is North-North, where many subsidiaries that supply goods to their parents are located in sectors in which both the input and final good are in the same industry. This is known as intra-industry VFDI. Intra-industry firms are generally located in high-skill countries and sectors that produce also high-skill inputs involving products that are at stages close to the parent firm's final stage of production. In contrast to inter-industry VFDI, this type of FDI is much harder to explain with the standard theories of VFDI, which emphasize factor cost differences as the primary motivation for fragmentation. Another possible explanation for this positive joint effect of the euro and the skill level of the host country is that US MNCs might be interested in acquiring skilled labour to access foreign pools of knowledge and technologies with the aim of augmenting their existing ownership advantages, a strategy consistent with asset-seeking FDI (Dunning, 2000). Concerning the total factor productivity of the host country, this covariate is relevant for the whole and EU samples. Its sign, as expected, is positive in the former, but negative in the latter. A possible reason for this finding is that Romania, whose US FDI stock is small in comparison with the Western EU countries, has high productivity levels, and therefore, could act as an outlier. Lastly, the fact that no labour variable is a potential US FDI determinant for EA core countries, could be indicative that VFDI loses relevance in favour of HFDI in these countries.

Regarding trade and openness measures, the different posterior means of the relevant 
covariates in this group does not allow us to opt for a particular US FDI strategy. However, once we study the euro effect, its interaction with trade openness of the host country is relevant for the whole sample and its posterior mean is positive. Moreover, the joint effect of the common currency and the mean tariff rate of the host country is negative and relevant for the EA and its periphery. All this taken together would mean that the process of monetary integration has encouraged VFDI strategies. As for worldwide openness, the KOF social globalization index has a positive sign for the whole sample, as expected.

The next group consist of investment openness variables. In those cases where the ChinnIto index of the host country and BIT (bilateral investment agreements) are relevant, their sign is positive, as expected. The same occurs with the variable black market exchange rate, an index measuring the absence of a black market exchange rate (where a value of 10 means full convertibility, see table 2).

Concerning institutional quality, we include several indexes from the ICRG and the Fraser Institute in order to measure the host country quality and efficiency of its institutions ${ }^{22}$. To ease the interpretation of the results, they have been defined so that a higher score is associated with better institutions (see table 2). Moreover, we also add the civil liberties and political rights indexes from the Freedom House. In this case, a larger score means a lower level of freedom. As for the results, the potential covariates for the whole sample point into different directions, probably due to the high degree of heterogeneity of the largest group. Law and order and civil liberties are robust US OFDI determinants with a positive and negative posterior mean, respectively. These effects are as expected, because higher quality and efficiency of institutions attracts $\mathrm{FDI}^{23}$. On the other hand, the protection of property rights in the destination country has a negative sign. At first sight, this sign may seem unexpected, but according to Lui (1985) and Egger and Winner (2005), multinational firms might be willing to accept paying bribes in order to speed up the bureaucratic processes.

\footnotetext{
${ }^{21}$ On the one hand, the positive sign of trade openness of the host country for the whole sample and EA core countries, as well as the negative sign of revenue from trade taxes for the whole sample, would imply that FDI and trade have been complements during the period considered (consistent with VFDI). Similar results were found by Helpman (1984), Helpman and Krugman (1985), Brainard (1997) and Camarero and Tamarit (2004). On the other hand, the mean tariff rate of the host country for the EA group and its periphery, and that one of the revenue from trade taxes for EU countries, would indicate a substitution pattern between trade and FDI and, thus, HFDI (Markusen, 1984; Markusen and Venables, 1999, 2000; Blonigen, 2001).

${ }^{22}$ These variables are corruption, democratic accountability, law and order, bureaucracy quality, protection of property rights, and integrity of the legal system.

${ }^{23}$ See, for example, (Wei, 2000; Chiappini, 2014; Kinoshita and Campos, 2003; Hyun, 2006)
} 
In this case, corruption acts as a "helping hand". As for the other country-groups, the corruption index in the EU countries and democratic accountability in the EA periphery have a negative sign. Some individual countries' inclusion in the groups may explain this result. Concerning the euro effect, its interaction with the corruption index is a robust determinant for EU countries. Its mean effect is positive. Consequently, among EU countries, the introduction of the common currency has played an important role attracting US FDI to these countries with better institutions.

Concerning the covariates labeled government size, government investment and the top marginal income tax of the host country present a negative sign. On the other hand, the mean effect of government consumption is positive and relevant for EA countries. Both signs are potentially possible: an increase in the government size implies lower fiscal freedom and high-taxation policy. Such situations could deter the entrance of FDI since high taxation would decrease returns on private investment (De Haan et al., 2006; Justesen, 2008; Cebula, 2011; Miller and Kim, 2016). Nevertheless, higher taxes could also attract FDI, because they could be indicative of significant spending on infrastructure, transportation systems and public investment (Justesen, 2008).

Related with the previous measures, in our work we have also included variables which represents banking and credit regulation. Bank ownership and interest rate controls (larger values imply lower level of interest rate controls) are potential US OFDI determinants for the whole sample. Its sign, as expected, is positive, as restrictive regulations tend to generate additional production and transaction costs, imposing burdens on private investment. Similar results were found by Ghazalian and Amponsem (2019).

Regarding monetary conditions, the level of inflation measured by the CPI, as well as the money growth of the host country are relevant FDI determinants for the EU sample. Their mean effect is negative, because volatile and unpredictable inflation discourages FDI. Moreover, high rates of inflation may also lead to domestic currency depreciation, which at the same time reduces the real value of earnings in local currency for market-seeking inward (HFDI) investing firms. VFDI could also be negatively affected by inflation, as an increase in the prices of locally sourced inputs makes the exporter country harder to maintain a cost advantage in foreign markets (Buckley et al. (2007)). Chiappini (2014) obtained similar results. 
Concerning the variables included in communications infrastructure, except for "Cellular" in the whole sample, the largest and most heterogeneous group, the rest of the measures with a PIP higher than 0.5 have a positive sign, as expected. Larger values imply more developed communications infrastructure. Similar results were found by Di Giovanni (2005) and Alfaro and Chen (2015).

Finally, the nominal exchange rate of the host country is a relevant covariate for EA countries as well as for the core. According to Benassy-Quere et al. (1999), an appreciation of the local currency increases FDI inflows due to the higher purchasing power of local consumers, but reduces them through lower competitiveness (higher labor costs) if FDI aims at producing for re-exporting. Moreover, a depreciation in the real exchange rate of the recipient country increases FDI through reduced cost of capital (Froot and Stein, 1991). In our case, an increase of the variable implies an appreciation of the US dollar (a depreciation of the host country currency) and the obtained the negative sign could be explained by US MNCs investing abroad to serve local markets (market-seeking FDI or HFDI) in the EA core countries.

Comparing the groups of countries, some additional insights can be gained. Concerning the larger group, the euro effect is very relevant, but most of the potential determinants are related to the traditional gravity variables, such as the size and population of the countries, density, etc. In addition, skills and labor productivity attract American FDI as well as different measures of openness, both in trade and investment. The institutions are relevant, especially those related to law and order as well as the banking system and credit. For the group of EU countries, that includes new and old members, as well as the UK, the euro effect remains very relevant, as well as the gravity variables (size) and the spatial lag and labor market variables. However, trade variables and institutions are not so important, probably because this group of countries already shares economic institutions via the EU. Taxes and tariffs are robust determinants in contrast to the whole group. Within the EU, if we restrict the group to euro countries, the two variables related to integration are again relevant, possibly once the UK is not in the group. Openness, market size and and labor-market determinants are also chosen, but the institutional variables are omitted, probably because euro and integration capture these effects. However it remains important to find out whether the US has different reasons to invest in the core of the EA and in the periphery. Once we divide the group, in the core the euro effect disappears, but economic 
integration remains; no labor market variable is relevant, whereas GDP and urban population have high inclusion probabilities. Trade openness and communications infrastructure, as well as the nominal exchange rate are the last relevant variables. In the periphery, the two integration variables have high probabilities attached and maintains GDP its interaction with the euro and urban population. However, no openness measure is relevant nor the exchange rate. Only tariffs and its interaction as well as democratic accountability (with a negative sign). Therefore, European integration has provided exchange rate and institutional stability, that has benefited especially to the most recent and peripheral members, gaining from the reputation of the older EU members. Europe is a very important market for US MNCs, but also vertical FDI is still relevant, as labor costs are still relatively low in some EA countries and the labor force is skilled and productive.

\section{Conclusions}

In this paper we analyse the determinants of the US OFDI stock of using a large sample of 56 host countries (that represent over $67 \%$ of total American FDI) during the period 19852017. In particular, to capture the role of the euro, we compare the most relevant covariates obtained for the whole group of countries with the sub-groups of EU and EA countries, and within this last group, to what we call its core and periphery. Although this variable selection exercise is relevant by itself, we also provide the posterior mean obtained for the variables selected in each sample. Tentatively, this allows us to discriminate among FDI locational theoretical approaches and assess how the euro has affected the determinants of US FDI for each group of countries.

Our research shows that many variables chosen in the previous FDI literature are not necessarily robust determinants. According to our BMA analysis, at most, only around the $50 \%$ of the potential covariates, 30 out of 63 , are relevant for the whole sample, our largest and most heterogeneous country group. Moreover, as expected, the results point to more parsimonious models when more homogeneous sub-samples are analyzed. For EU countries, 19 variables are robust US FDI determinants, 17 in the EA sample, and for core and peripheral countries 7 and 10, respectively. Our main findings suggest that US FDI is explained by both horizontal and vertical FDI motives in all country groups. However, HFDI strategies predominate in EA core countries, whereas VFDI prevails in the EA periphery. 
As for the euro effect, the adoption of the common currency has played an important role encouraging US FDI not only when we analyse the whole sample, but also EU and EA countries, and within this last group, the peripheral ones. Concerning the role of the euro in the EA periphery, the common currency has encouraged US FDI towards those destinations, mostly attracted by relatively skilled labor force and lower costs. Therefore, joining the euro has been an important element in the convergence process of EA peripheral countries to the core, as these peripheral countries have become important investment destinations for US MNCs. In addition, we also find that the interaction of our variable euro with other relevant measures play a role to explain the concentration of US FDI in Europe. Our results indicate that market size has been losing relevance, thereby suggesting that the single currency may have been to the detriment of HFDI. This is because the euro has mainly favoured VFDI strategies, as we can derived from our results on labour and trade measures. Finally, we can also conclude that the adoption of the common currency has encouraged US OFDI to that countries that have higher quality of institutions. 


\section{References}

Alfaro, L. and Charlton, A. (2009). Intra-Industry Foreign Direct Investment. American Economic Review, 99(5):2096-2119.

Alfaro, L. and Chen, M. X. (2015). Multinational Activity and Information and Communication Technology. Working Paper, May. Background Note, World Development Report 2016., pages 1-28.

Anderson, J. E. and Wincoop, E. v. (2003). Gravity with Gravitas : A Solution to the Border Puzzie. The American Economic Review, 93(1):170-192.

Antonakakis, N. and Tondl, G. (2015). Robust determinants of OECD FDI in developing countries: Insights from bayesian model averaging. Cogent Economics and Finance, 3(1):1-25.

Baier, S. L. and Bergstrand, J. H. (2007). Do free trade agreements actually increase members' international trade? Journal of International Economics, 71(1):72-95.

Baldwin, R., Di Nino, V., Fontagné, L., De Santis, R., and Taglioni, D. (2008). Study on the Impact of the Euro on Trade and Foreign Direct Investment. European Economy, Economics Paper, 321.

Bayarri, M. J., Berger, J. O., Forte, A., and García-Donato, G. (2012). Criteria for bayesian model choice with application to variable selection. Annals of Statistics, 40(3):1550-1577.

Bayoumi, T. and Eichengreen, B. (1993). Shocking Aspects of European Monetary Union. Adjustment and Growth in the European Monetary Union, (3949):193-229.

Benassy-Quere, A., Fontagne, L., and Lahreche-Revil, A. (1999). Exchange Rate Strategies in the Competition for Attracting FDI. CEPII Working Paper, 99(16):3-34.

Benkovskis, K., Bluhm, B., Bobeica, E., Osbat, C., and Zeugner, S. (2019). What drives export market shares? It depends! An empirical analysis using Bayesian model averaging. Empirical Economics, pages 1-34.

Berger, J. O. and Pericchi, L. R. (2001). Objective Bayesian Methods for Model Selection: Introduction and Comparison. Lecture Notes - Monograph Series, 38:135-207.

Berger, J. O. and Sellke, T. (1987). Testing a Point Null Hypothesis: The Irreconcilability of P Values and Evidence. Journal of the American statistical Association, 82(397):112-122.

Bergstrand, J. and Egger, P. (2007). A knowledge-and-physical-capital model of international trade flows, foreign direct investment, and multinational enterprises. Journal of International Economics, 73(2):278-308.

Billington, N. (1999). The location of foreign direct investment: an empirical analysis. Applied Economics, 31(1):65-76.

Blanchard, O. and Acalin, J. (2016). Policy Brief 16-17: What Does Measured FDI Actually Measure? Peterson Institute for International Economics. 
Blonigen, B. A. (1997). Frim-specific assets and the link between exchange rates and foreign direct investment. The American Economic Review, 87(3):447-465.

Blonigen, B. A. (2001). In Search Of Substitution Between Foreign Production And Exports. Journal of International Economics, 53(1):81-104.

Blonigen, B. A., Davies, R. B., and Head, K. (2003). Estimating the knowledge-capital model of the multinational enterprise: Comment. American Economic Review, 93(3):980-994.

Blonigen, B. A., Davies, R. B., Waddell, G. R., and Naughton, H. T. (2007). FDI in space: Spatial autoregressive relationships in foreign direct investment. European Economic Review, 51(5):1303-1325.

Blonigen, B. A. and Piger, J. M. (2014). Determinants of foreign direct investment. Canadian Journal of Economics, 47(3):775-812.

Brainard, S. L. (1997). An Empirical Assessment of the Proximity-Concentration Trade-off between Multinational Sales and Trade. American Economic Review, 87(4):520-544.

Brouwer, J., Paap, R., and Viaene, J. M. (2008). The trade and FDI effects of EMU enlargement. Journal of International Money and Finance, 27(2):188-208.

Bruno, R., Campos, N., Estrin, S., and Tian, M. (2016). Technical Appendix to "The Impact of Brexit on Foreign Investment in the UK ". Gravitating Towards Europe : An Econometric Analysis of the FDI Effects of EU Membership. Retrieved from http://cep.lse.ac.uk/pubs/download/brexit03_technical_paper.pdf.

Buckley, P. J., Clegg, L. J., Cross, A. R., Liu, X., Voss, H., and Zheng, P. (2007). The determinants of Chinese outward foreign direct investment. Journal of International Business Studies, 38(4):499-518.

Busse, M., Königer, J., and Nunnenkamp, P. (2010). FDI promotion through bilateral investment treaties: More than a bit? Review of World Economics, 146(1):147-177.

Camarero, M., Forte, A., Garcia-Donato, G., Mendoza, Y., and Ordoñez, J. (2015). Variable selection in the analysis of energy consumption-growth nexus. Energy Economics, 52:207-216.

Camarero, M., Gómez-Herrera, E., and Tamarit, C. (2018). New Evidence on Trade and FDI: how Large is the Euro Effect? Open Economies Review, 29(2):451-467.

Camarero, M., Montolio, L., and Tamarit, C. (2019). What drives German foreign direct investment? New evidence using Bayesian statistical techniques. Economic Modelling, 83:326-345.

Camarero, M. and Tamarit, C. (2004). Estimating the export and import demand for manufactured goods: The role of FDI. Review of World Economics, 140(3):347-375.

Campos, N. F. (2019). The Economics of a Brexit. The New Palgrave Dictionary of Economics, pages 1-15.

Campos, N. F., Coricelli, F., and Moretti, L. (2019). Institutional integration and economic growth in Europe. Journal of Monetary Economics, 103:88-104. 
Carr, B. D. L., Markusen, J. R., and Maskus, K. E. (2001). Estimating the Knowledge-Capital Model of the Multinational Enterprise. The American Economic Review, 93(3):995-1001.

Carril-Caccia, F. and Pavlova, E. (2018). Foreign direct investment and its drivers: a global and EU perspective. ECB Economic Bulletin, (4):60-78.

Cebula, R. J. (2011). Economic Growth, Ten Forms of Economic Freedom, and Political Stability: An Empirical Study Using Panel Data, 2003-2007. Journal of Private Enterprise, 26(2):61-81.

Chakrabarti, A. (2001). The Determinants of Foreign Direct Investment : Sensitivity Analyses of Cross-Country Regressions. KYKLOS, 54(1):89-114.

Chaney, T. (2008). Distorted Gravity: The Intensive and Extensive Margins of International Trade. American Economic Review, 98(4):1707-1721.

Chiappini, R. (2014). Institutional Determinants of Japanese Outward FDI in The Manufacturing Industry. GREDEG Working Papers, 2014(11):1-27.

Chinn, M. D. and Ito, H. (2006). What matters for financial development? Capital controls, institutions, and interactions. Journal of Development Economics, 81(1):163-192.

Coeurdacier, N., Barany, Z., and Guibaud, S. (2018). Capital Flows in an Aging World. CEPR Discussion Paper, 13180:1-30.

Crozet, M., Mayer, T., and Mucchielli, J. L. (2004). How do firms agglomerate? A study of FDI in France. Regional Science and Urban Economics, 34(1):27-54.

De Haan, J., Lundström, S., and Sturm, J. E. (2006). Market-oriented institutions and policies and economic growth: A critical survey. Journal of Economic Surveys, 20(2):157-191.

De Sousa, J. and Lochard, J. (2011). Does the single currency affect foreign direct investment? Scandinavian Journal of Economics, 113(3):553-578.

Desbordes, R., Koop, G., and Vicard, V. (2018). One size does not fit all. . p panel data: Bayesian model averaging and data poolability. Economic Modelling, 75(July):364-376.

Dhingra, S., Ottaviano, G., Sampson, T., and Reenen, J. V. (2016). The impact of Brexit on foreign investment in the UK. London School of Economics and Political Science, pages 1-12.

Di Giovanni, J. (2005). What drives capital flows? The case of cross-border M\&A activity and financial deepening. Journal of International Economics, 65(1):127-149.

Disdier, A. C. and Head, K. (2008). The puzzling persistence of the distance effect on bilateral trade. Review of Economics and Statistics, 90(1):37-48.

Disdier, A. C. and Mayer, T. (2004). How different is Eastern Europe? Structure and determinants of location choices by French firms in Eastern and Western Europe. Journal of Comparative Economics, 32(2):280-296. 
Dunning, J. H. (1977). Trade, Location of Economic Activity and the Multinational Enterprise: A Search for an Eclectic Approach. In The International Allocation of Economic Activity, pages 395-418.

Dunning, J. H. (1979). Explaining Changing Patterns of International Production: In Defense of the Electric Approach. Oxford Bulletin of Economics and Statistics, 41(4):269-295.

Dunning, J. H. (1980). Theory Toward an Eclectic Production : of International Tests Some Empirical. Journal of International Business Studies, 11:9-31.

Dunning, J. H. (2000). The eclectic paradigm as an envelope for economic and business theories of MNE activity. International Business Review, 9(2):163-190.

Dür, A., Baccini, L., and Elsig, M. (2014). The design of international trade agreements: Introducing a new dataset. Review of International Organizations, 9(3):353-375.

Eaton, J. and Tamura, A. (1994). Bilateralism and regionalism in japanese and u.s. trade and direct foreign investment patterns. Journal of The Japanese and International Economies, 8(4):478-510.

Egger, P. and Winner, H. (2005). Evidence on corruption as an incentive for foreign direct investment. European Journal of Political Economy, 21(4):932-952.

Eicher, T. S., Helfman, L., and Lenkoski, A. (2012). Robust FDI determinants: Bayesian Model Averaging in the presence of selection bias. Journal of Macroeconomics, 34(3):637-651.

Ekholm, K., Forslid, R., and Markusen, J. (2007). Export-platform Foreign Direct Investment. Journal of the European Economic Association, 5(4):776-795.

European Comission (2019). Foreign Direct Investment in the EU. Commission Staff Working Document, SWD (2019).

Feldkircher, M. and Zeugner, S. (2009). Benchmark Priors Revisited:on Adaptive Shrinkage and the Supermodel Effect in Bayesian Model Averaging. IMF Working Papers, 09(202):1-43.

Fernández, C., Ley, E., and Steel, M. F. J. (2001). Model uncertainty in cross-country growth regressions. Journal of Applied Econometrics, 16(5):563-576.

Fernández-Val, I. and Weidner, M. (2016). Individual and time effects in nonlinear panel models with large N, T. Journal of Econometrics, 192(1):291-312.

Fernández-Val, I. and Weidner, M. (2018). Fixed Effects Estimation of Large- T Panel Data Models. Annual Review of Economics, 10(1):109-138.

Flam, H. and Nordstrom, H. (2008). The Euro Impact on FDI Revisited and Revised. mimeo, (December 2008).

Forte, A., Garcia-Donato, G., and Steel, M. (2018). Methods and Tools for Bayesian Variable Selection and Model Averaging in Normal Linear Regression. International Statistical Review, 86(2):237-258. 
Froot, K. A. and Stein, J. C. (1991). Review of Economics and Statistics. The Quarterly Journal of Economics, 106(4):1191-1217.

García-Donato, G. and Forte, A. (2015). BayesVarSelect v. 1.6.0 R Package.

García-Donato, G. and Martínez-Beneito, M. A. (2013). On sampling strategies in Bayesian variable selection problems with large model spaces. Journal of the American Statistical Association, 108(501):340-352.

George, E. I. and McCulloch, R. E. (1997). Approaches for bayesian variable selection. Statistica Sinica, 7(2):339373.

Ghazalian, P. L. and Amponsem, F. (2019). The effects of economic freedom on FDI inflows: an empirical analysis. Applied Economics, 51(11):1111-1132.

Gygli, S., Haelg, F., Potrafke, N., and Sturm, J.-E. (2019). The KOF Globalisation Index -revisited. The Review of International Organizations, 14(3):543-574.

Head, K. and Mayer, T. (2004). Market Potential and the Location of Japanese Investment in the European Union. Review of Economics and Statistics, 86(4):959-972.

Head, K. and Mayer, T. (2014). Gravity Equations: Workhorse,Toolkit, and Cookbook. In Gopinath, G., Helpman, E., and Rogoff, K., editors, Handbook of International Economics, volume 4, chapter 3, pages 131-195. Elsevier B.V, 1 edition.

Head, K. and Ries, J. (2008). FDI as an outcome of the market for corporate control: Theory and evidence. Journal of International Economics, 74(1):2-20.

Helpman, E. (1984). A Simple Theory of International Trade with Multinational Corporations. Journal of Political Economy, 92(3):451-471.

Helpman, E. (2006). Trade, Fdi, and the Organization of Firms. Journal of Economic Literature, 44(September):589-630.

Helpman, E. and Krugman, P. (1985). Market structure and foreign trade: Increase Returns Imperfect Competition: Increasing Returns, Imperfect Competition, and the International Economy. MIT Press, Cambridge, MA.

Hyun, H. J. (2006). Quality of institutions and foreign direct investment in developing countries: Causality tests for cross-country panels. Journal of Business Economics and Management, 7(3):103-110.

Jordan, A. and Lenkoski, A. (2018). Tobit Bayesian Model Averaging and the Determinants of Foreign Direct Investment. Mimeo, pages 1-27.

Justesen, M. K. (2008). The effect of economic freedom on growth revisited: New evidence on causality from a panel of countries 1970-1999. European Journal of Political Economy, 24(3):642-660.

Khayat, S. H. (2017). Oil and the Location Determinants of Foreign Direct Investment Inflows to Mena Countries. Journal of International Business Research, 16(1):1-31. 
Kim, z. K. (2004). The Impact of the Process of Economic Integration on the Relationships between Foreign Direct Investment (FDI) and Trade: Cases of Japan and U.S. in European Union. International Area Studies Review, 7(2):135-148.

Kinoshita, Y. and Campos, N. F. (2003). Why Does Fdi Go Where it Goes? New Evidence From the Transition Economies. IMF Working Papers, 03(228):1-31.

Kleinert, J. and Toubal, F. (2010). Gravity for FDI. Review of International Economics, 18(1):1-13.

Konstantakopoulou, I. and Tsionas, E. (2011). The business cycle in eurozone economies (1960 to 2009). Applied Financial Economics, 21(20):1495-1513.

Kox, H. L. M. and Rojas-Romagosa, H. (2019). Gravity estimations with FDI bilateral data: Potential FDI effects of deep preferential trade agreements. KVL Economic Policy Research, 01.

Liang, F., Paulo, R., Molina, G., Clyde, M. A., and Berger, J. O. (2008). Mixtures of g priors for Bayesian variable selection. Journal of the American Statistical Association, 103(481):410-423.

Lui, F. T. (1985). An equilibrium queuing model of bribery. Journal of Political Economy, 93(4):760-781.

Machin, S. (2001). The changing nature of labour demand in the new economy and skill-biased technology change. Oxford Bulletin of Economics and Statistics, 63(Special Issue):753-776.

Markusen, J. R. (1984). Multinationals, multi-plant economies, and the gains from trade. Journal of International Economics, 16(3-4):205-226.

Markusen, J. R. and Maskus, K. E. (2002). Discriminating among alternative theories of the multinational enterprise. Review of International Economics, 10(4):694-707.

Markusen, J. R., Venables, A., Konan, D. E., and Zhang, K. H. (1996). A unified treatment of horizontal direct investment, vertical direct investment, and the pattern of trade in goods and services. NBER Working Paper Series, 5696:1-35.

Markusen, J. R. and Venables, A. J. (1999). Multinational firms and the new trade theory. Journal of International Economics, Elsevier, 462:183-203.

Markusen, J. R. and Venables, A. J. (2000). The theory of endowment, intra-industry and multi-national trade. Journal of International Economics, 52(2):209-234.

Martí, J., Alguacil, M., and Orts, V. (2017). Location choice of Spanish multinational firms in developing and transition economies. Journal of Business Economics and Management, 18(2):319-339.

McIntosh, S. (2002). The Changing Demand for Skills. European Journal of Education, 37(3):229-242.

Miller, T. and Kim, A. B. (2016). 2016 Index of Economic Freedom: Promoting Economic Opportunity and Prosperity. Washington, DC: Heritage Foundation. 
Moral-Benito, E. (2013). Likelihood-based estimation of dynamic panels with predetermined regressors. Journal of Business and Economic Statistics, 31(4):451-472.

Narciso, A. (2010). The impact of population ageing on international capital flow. SSRN Electronic Journal, pages $1-28$.

Neary, J. P. (2009). Trade costs and foreign direct investment. International Review of Economics and Finance, 18(2):207-218.

Neumayer, E. and Spess, L. (2005). Do bilateral investment treaties increase foreign direct investment to developing countries? World Development, 33(10):1567-1585.

Noorbakhsh, F., Paloni, A., and Youssef, A. (2001). Human capital and FDI inflows to developing countries: New empirical evidence. World Development, 29(9):1593-1610.

Othman, N., Yusop, Z., Andaman, G., and Ismail, M. M. (2018). Impact of government spending on fdi inflows: The case of asean-5, China and India. International Journal of Business and Society, 19(2):401-414.

Petroulas, P. (2007). The effect of the euro on foreign direct investment. European Economic Review, 51(6):14681491.

Raftery, A. E. (1995). Bayesian Model Selection in Social Research. Sociological Methodology, 25:111-163.

Rose-Ackerman, S. and Tobin, J. (2005). Foreign Direct Investment and the Business Environment in Developing Countries: The Impact of Bilateral Investment Treaties. Yale Law and Economics Research Paper, 293:1-74.

Salem Musibah, A. (2017). Political Stability and Attracting Foreign Direct Investment: a Comparative Study of Middle East and North African Countries. Sci.Int.(Lahore), 29(3):679-683.

Shah, N. and Iqbal, Y. (2016). Impact of Government Expenditure on the attraction of FDI in Pakistan. International Journal of Economics and Empirical Research, 4(4):212-219.

Sondermann, D. and Vansteenkiste, I. (2019). Did the Euro Change the Nature of FDI Flows Among Member States? European Central Bank. Working Paper Series, 2275.

Stojkov, A. and Warin, T. (2018). EU Membership and FDI: Is There an Endogenous Credibility Effect? Journal of East-West Business, 24(3):144-169.

Straathof, B., Linders, G., Lejour, A., and Jan, M. (2008). The Internal Market and the Dutch economy: Implications for trade and economic growth. CPB Netherlands Bureau for Economic Policy Analysis, 168.

Treasury, H. (2016). HM Treasury analysis: the long-term economic impact of EU membership and the alternatives. Parliament by the Chancellor of the Exchequer by command of Her Majesty, April:1-201.

Wei, S.-J. (2000). Local Corruption and Global Capital Flows. Review of Economics and Statistics, 82(1):1-11.

Weidner, M. and Zylkin, T. (2019). Bias and Consistency in Three-way Gravity Models. mimeo, pages 1-56. 
Yeaple, S. R. (2003). The Role of Skill Endowments in the Structure of U.S. Outward Foreign Direct Investment. Review of Economics and Statistics, 85(3):726-734.

Zhang, W. and Artis, M. J. (2001). Core and Periphery in EMU: A Cluster Analysis. Economic Issues, 6(2):39-59. 


\section{Table 1: Samples of countries}

\begin{tabular}{|c|c|c|}
\hline $\begin{array}{l}\text { Sample } \\
\text { of countries }\end{array}$ & Countries included & $\begin{array}{l}\text { Number } \\
\text { of countries }\end{array}$ \\
\hline Whole sample & $\begin{array}{l}\text { Argentina, Australia, Austria, Belgium, Bolivia, Brazil, Canada, Chile, } \\
\text { China, Colombia, Costa Rica, Cyprus, Denmark, Dominican Repub- } \\
\text { lic, Ecuador, Egypt, Finland, France, Germany, Greece, Guatemala, } \\
\text { Honduras, Hungary, India, Indonesia, Ireland, Israel, Italy, Jamaica, } \\
\text { Japan, Kenya, Malaysia, Mexico, Morocco, Netherlands, New Zealand, } \\
\text { Nicaragua, Norway, Panama, Paraguay, Peru, Philippines, Poland, Por- } \\
\text { tugal, Republic of Korea, Romania, Senegal, South Africa, Spain, Sri } \\
\text { Lanka, Sweden, Switzerland, Thailand, Turkey, United Kingdom, and } \\
\text { Uruguay }\end{array}$ & 56 \\
\hline EU countries & $\begin{array}{l}\text { Austria, Belgium, Cyprus, Denmark, Finland, France, Germany, Greece, } \\
\text { Hungary, Ireland, Italy, Netherlands, Poland, Portugal, Romania, Spain, } \\
\text { Sweden and United Kingdom. }\end{array}$ & 18 \\
\hline EA countries & $\begin{array}{l}\text { Austria, Belgium, Cyprus, Finland, France, Germany, Greece, Ireland, } \\
\text { Italy, Netherlands, Portugal, Spain. }\end{array}$ & 12 \\
\hline $\begin{array}{l}\text { EA core coun- } \\
\text { tries }\end{array}$ & Austria, Belgium, France, Germany and Netherlands. & 5 \\
\hline $\begin{array}{l}\text { EA peripheral } \\
\text { countries }\end{array}$ & Cyprus, Finland, Greece, Ireland, Italy, Portugal and Spain. & 7 \\
\hline
\end{tabular}

NOTE: We exclude from our sample the micro-states where US MNCs invests largely. The reason is that most FDI to these countries is not reflecting decisions based on long-run factors. A large proportion of these FDI outflows are just flows going in and out of the country on their way to their final destination, with this stop due to the favorable corporate tax conditions of the host country (see Blanchard and Acalin (2016)). These are the cases of Antigua and Barbuda, Bahamas, Barbados, Bermuda, Fiji, Grenada, Hong Kong, Luxembourg, Mauritius, Singapore and Trinidad and Tobago. 


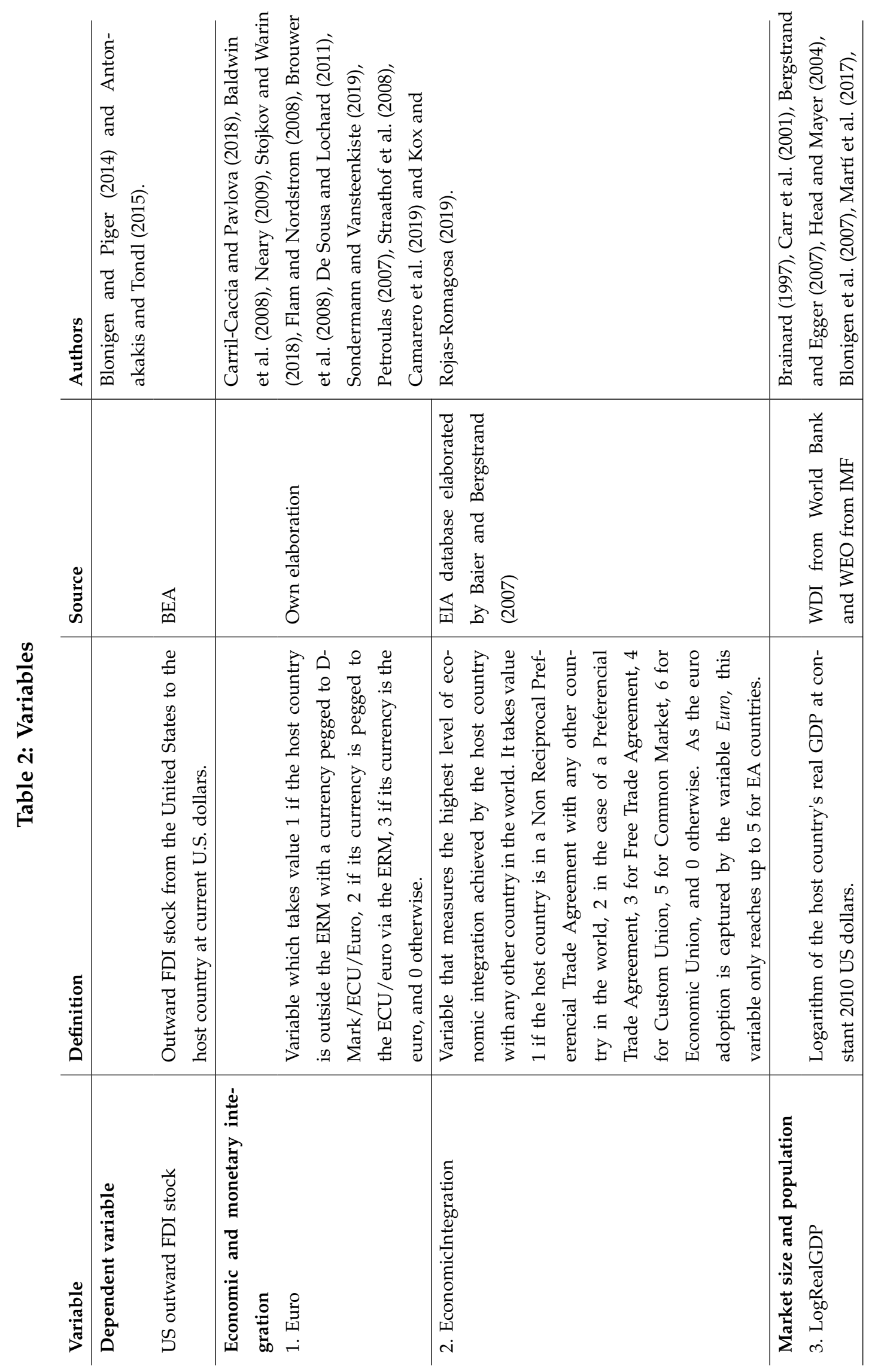




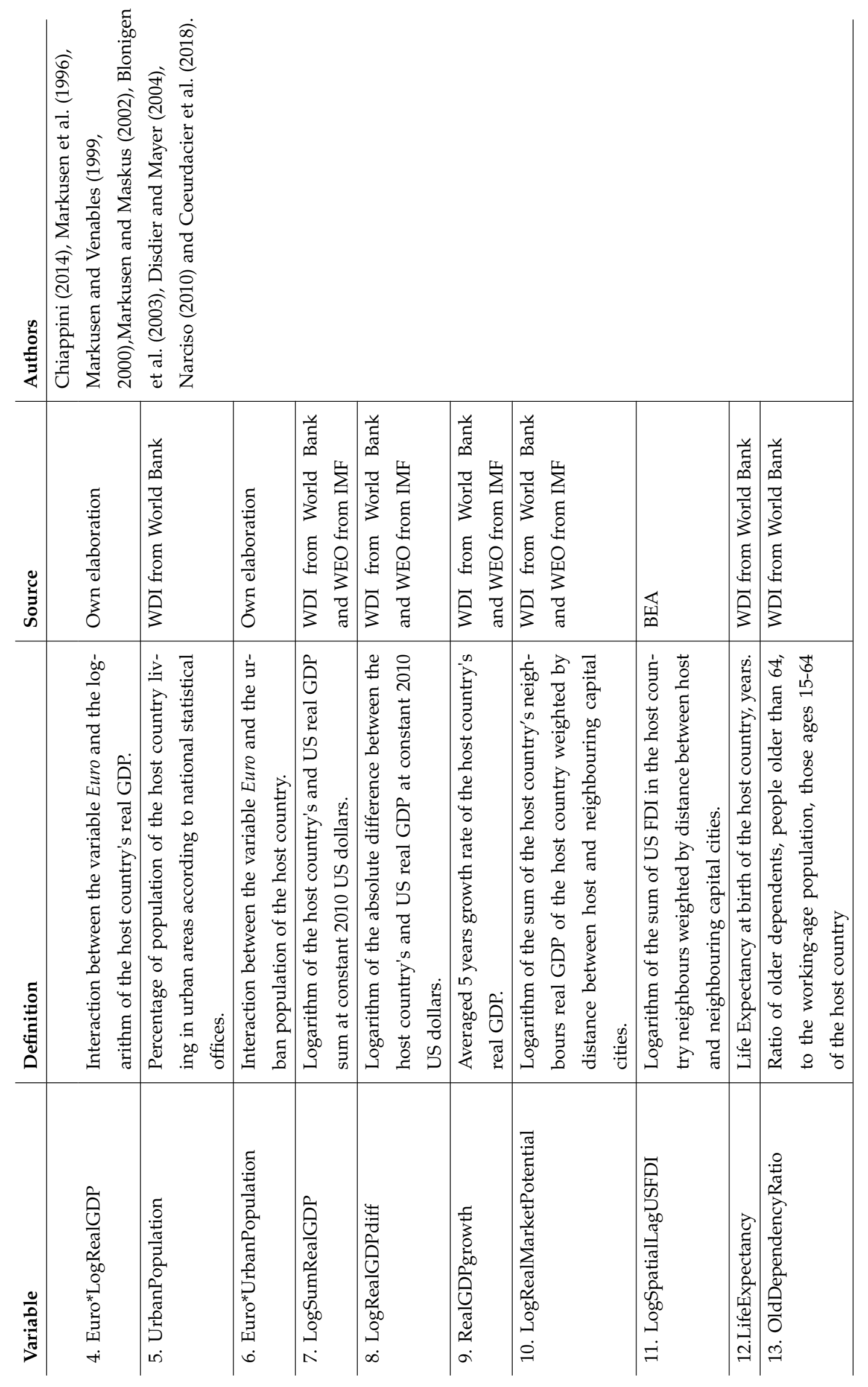



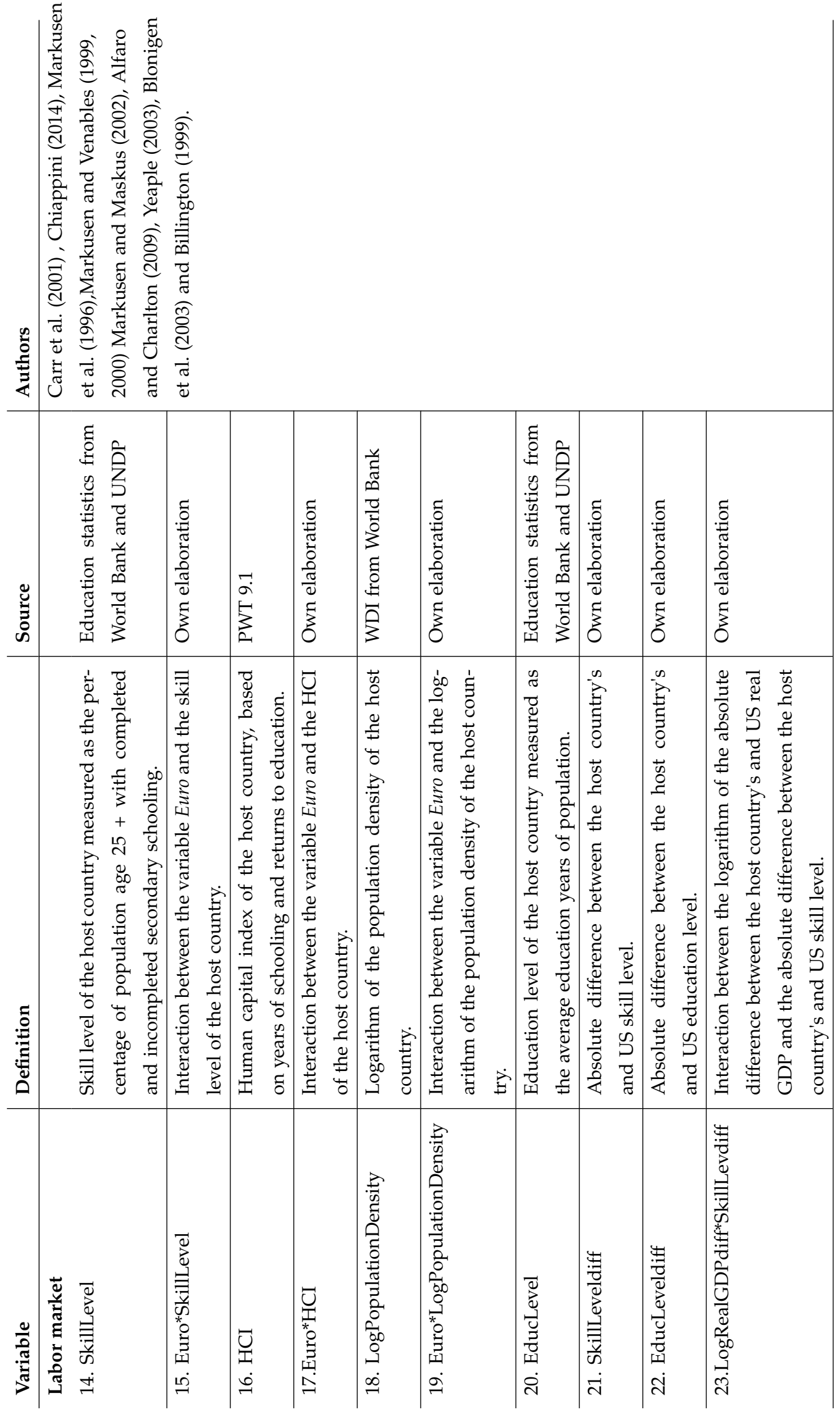


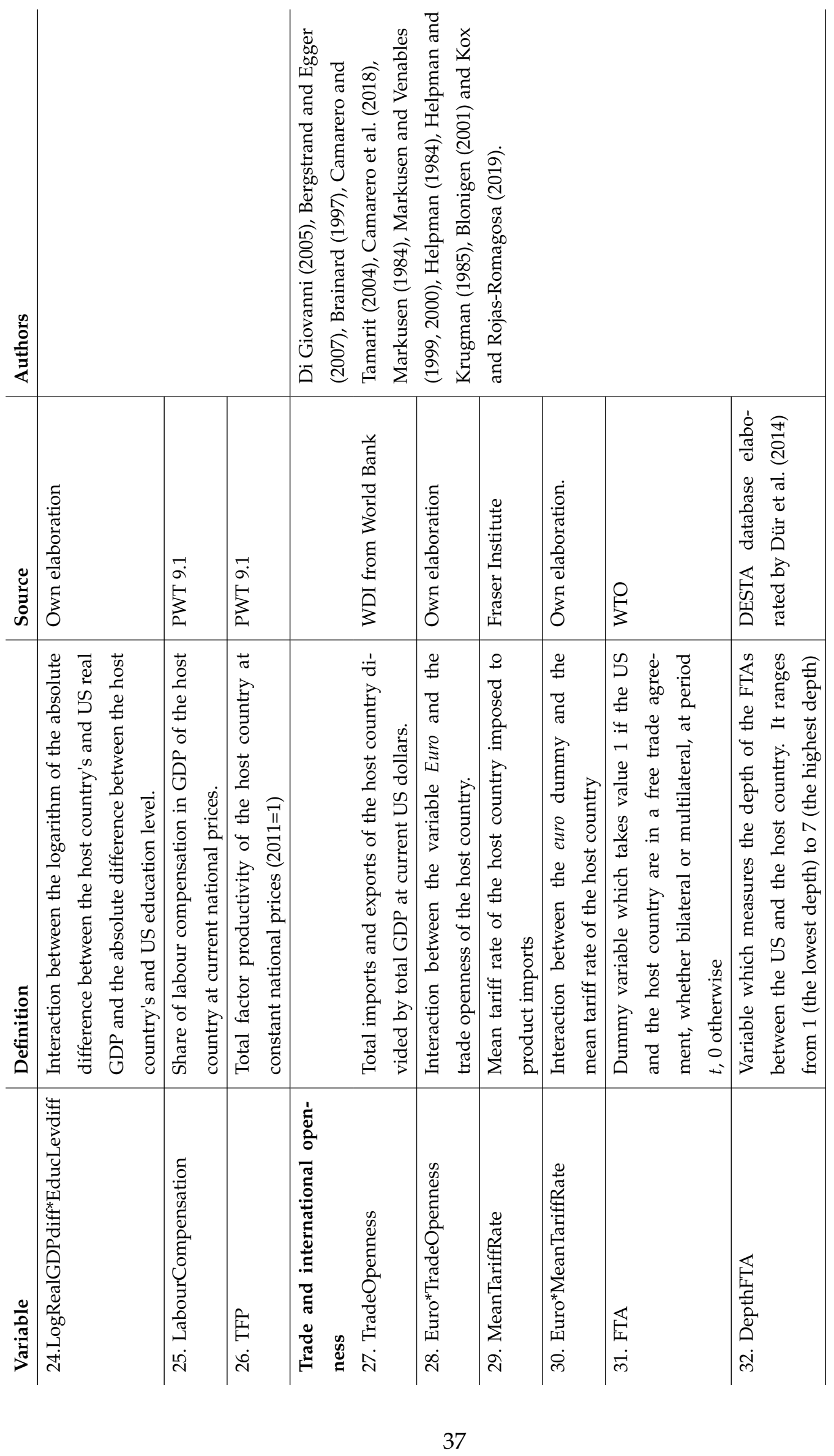




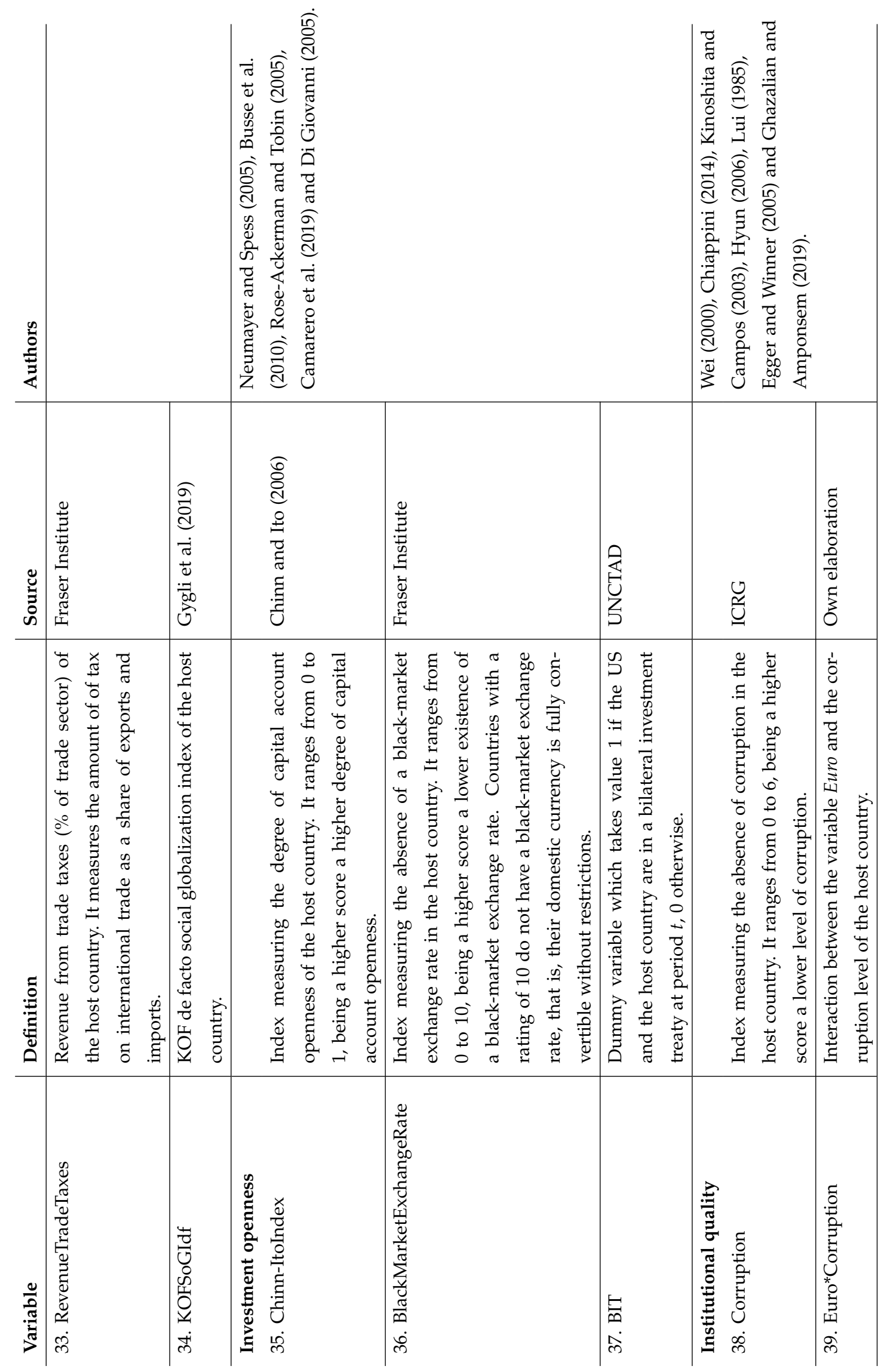




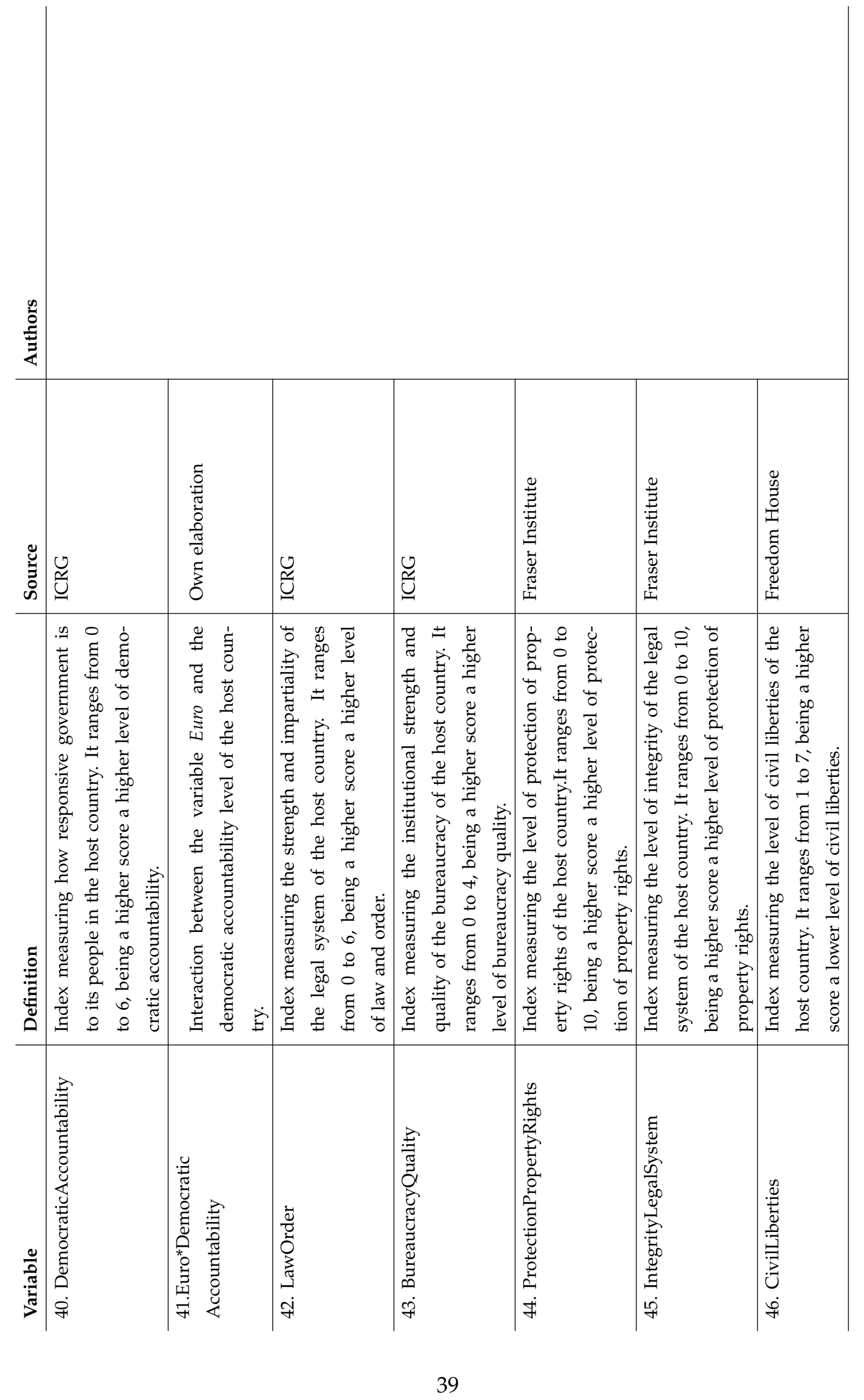




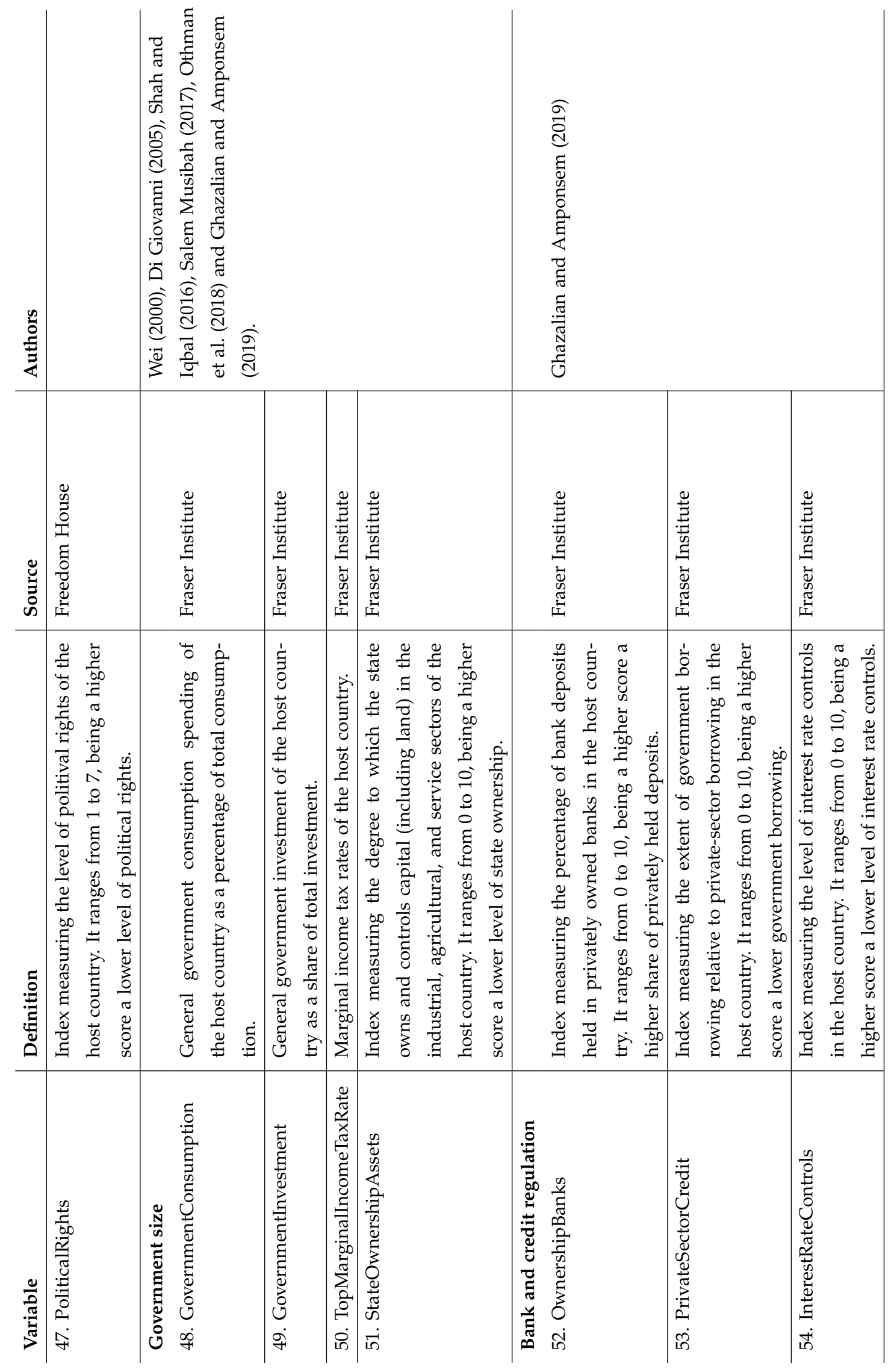




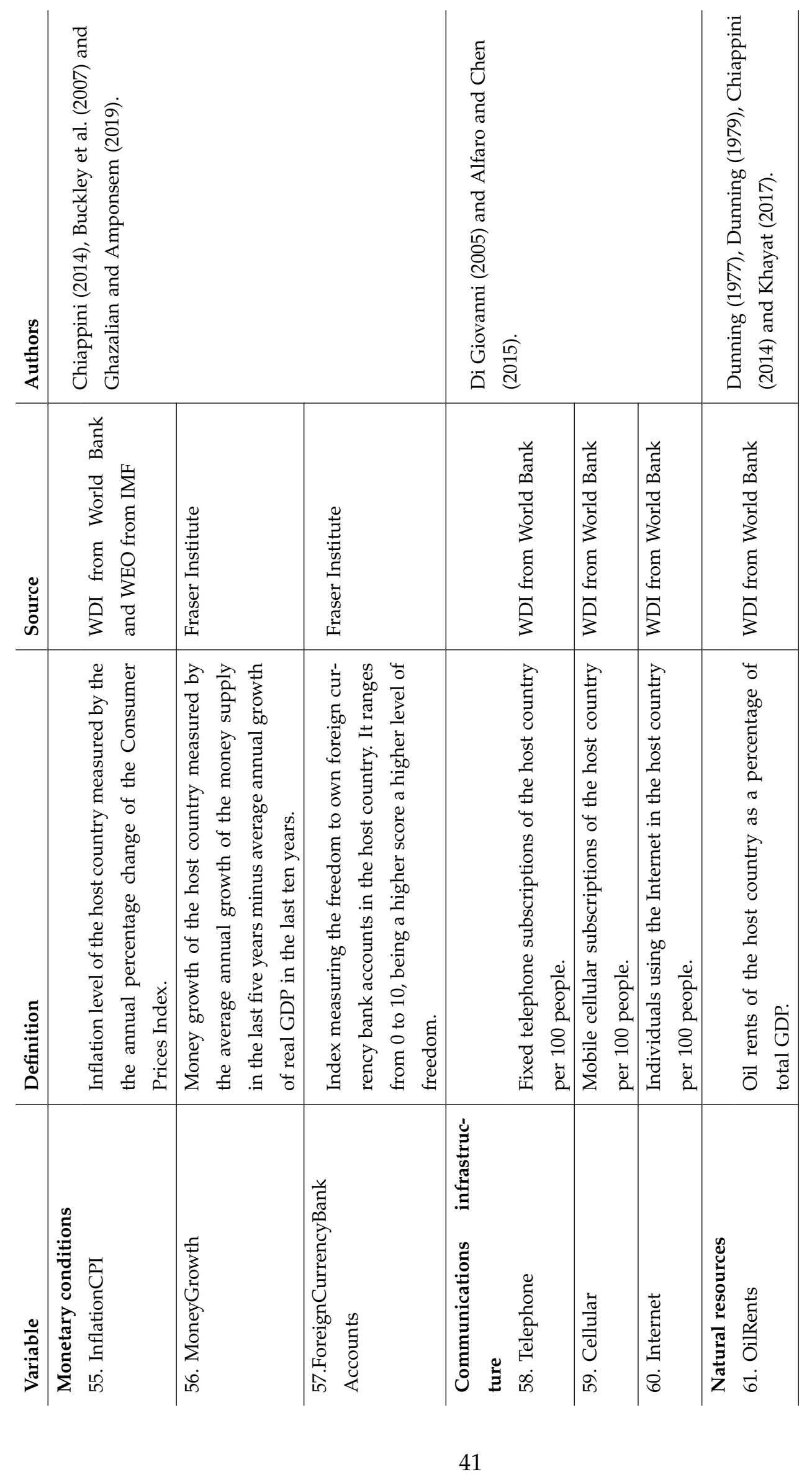




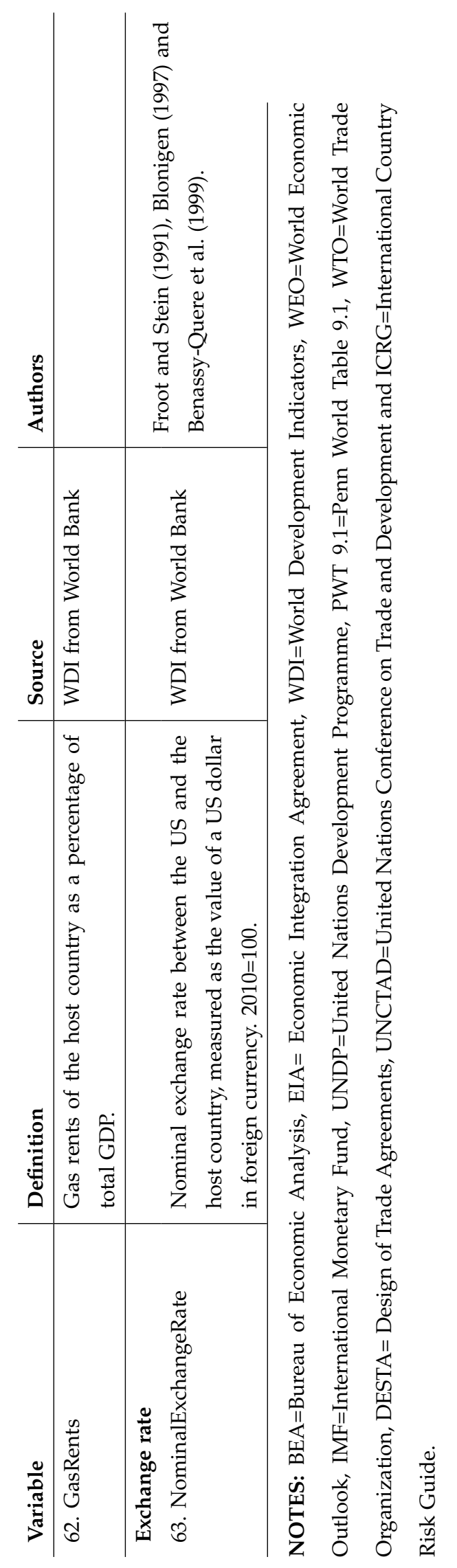




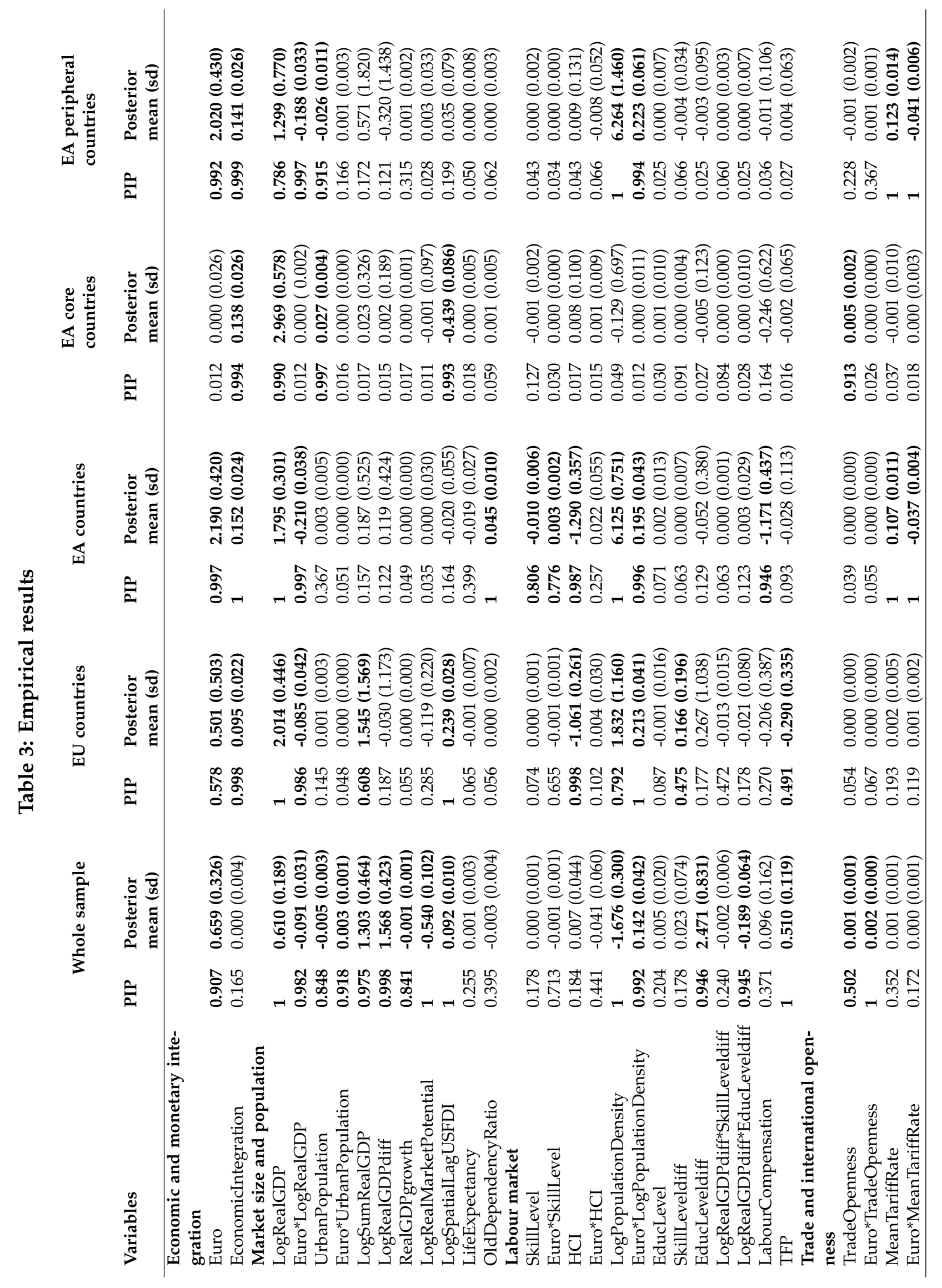




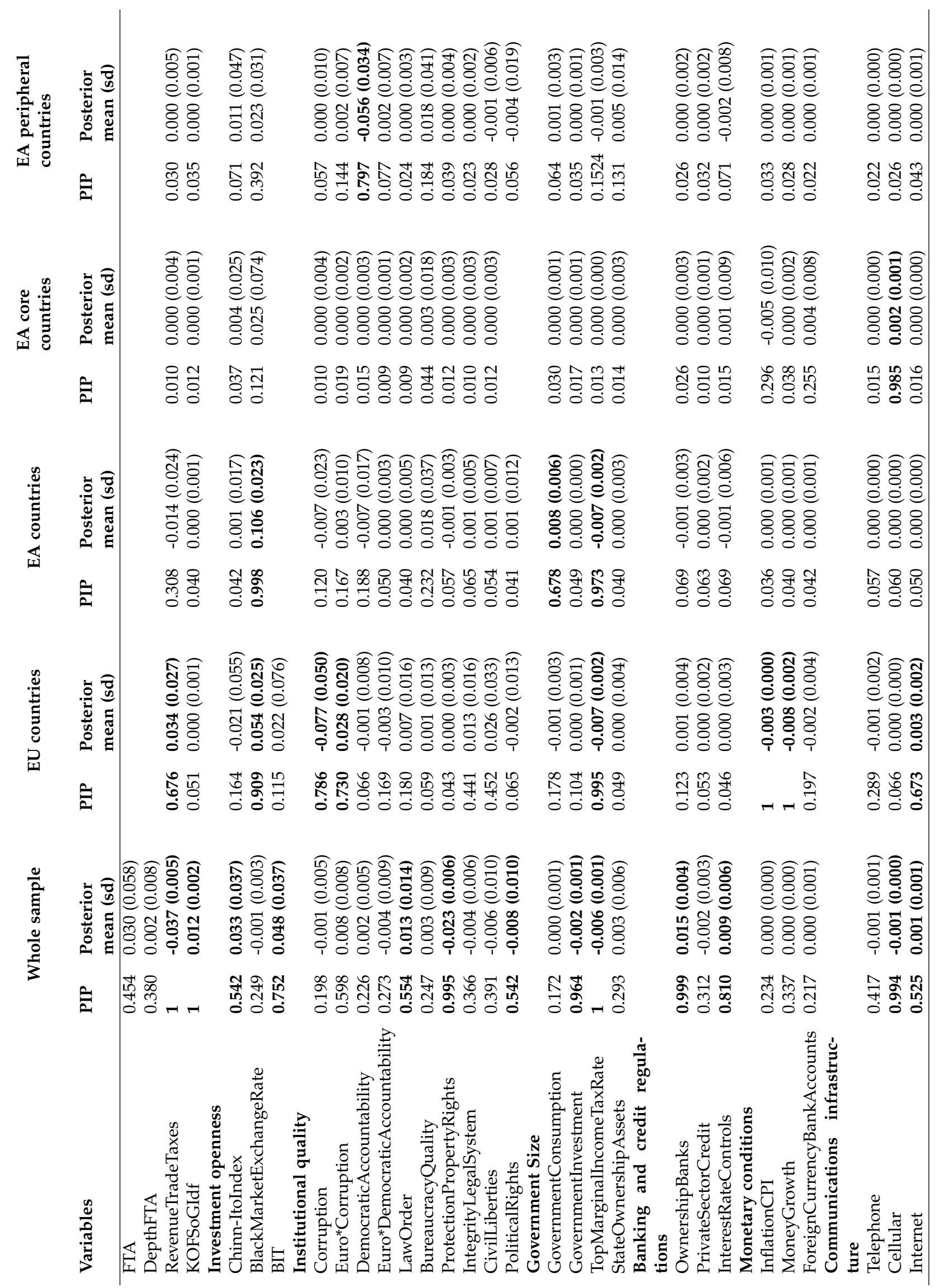




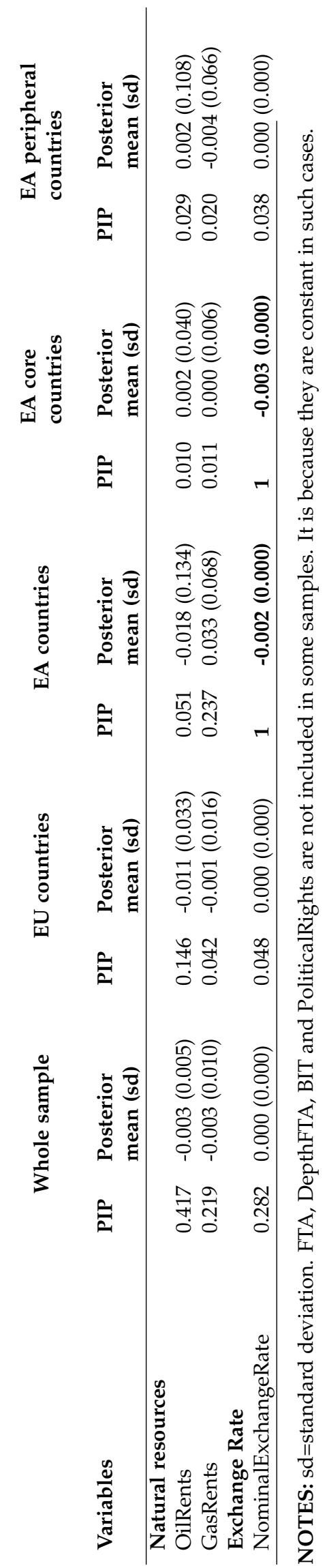




\section{Appendix A Trace of posterior inclusion probabilities}

The following trace plots are obtained from 20000 iterations, the maximum that the Rfunction GibbsBvs allows to elaborate such plots. The PIPs are very close to converge with such number of iterations.

Figure 1: Whole sample trace estimation

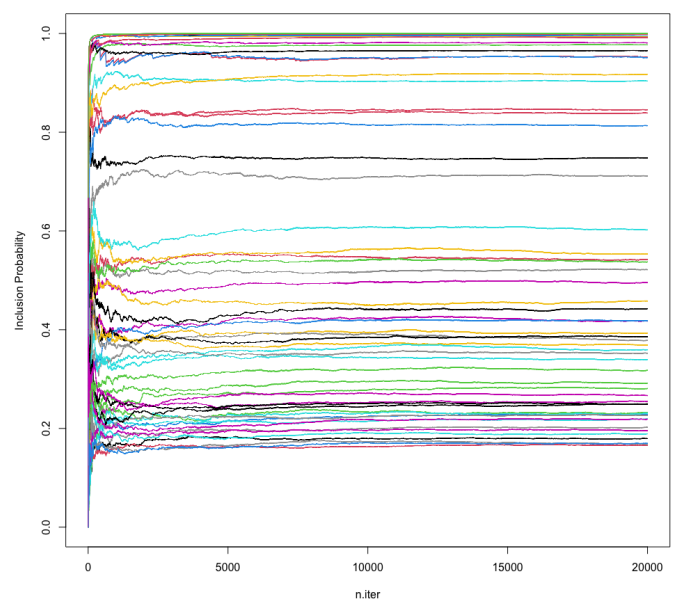

Figure 2: EU countries trace estimation

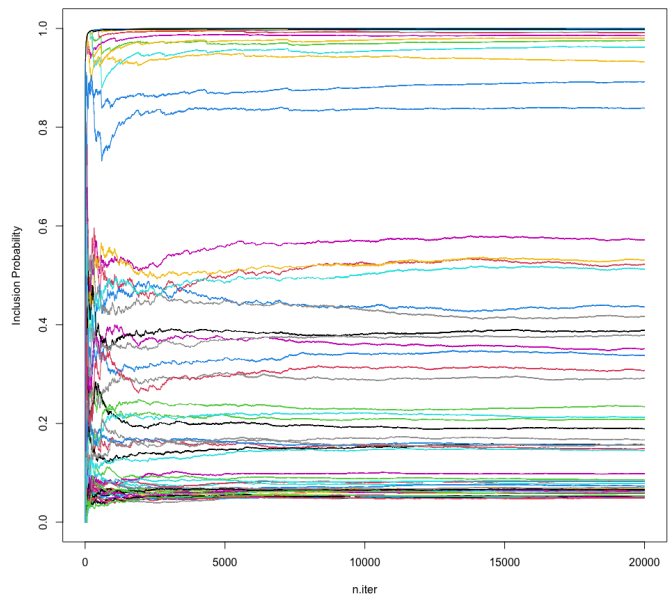


Figure 3: EA countries trace estimation

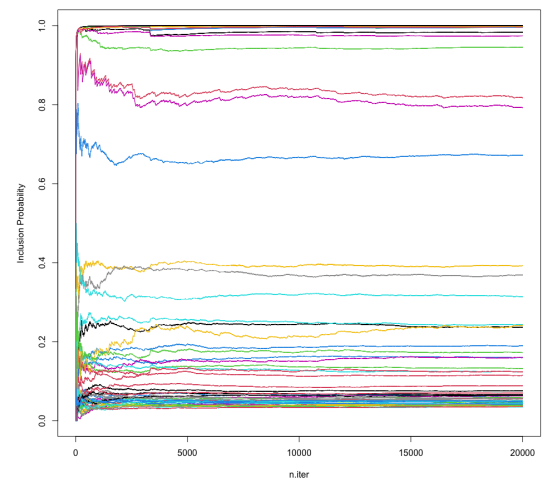

Figure 4: EA core countries trace estimation

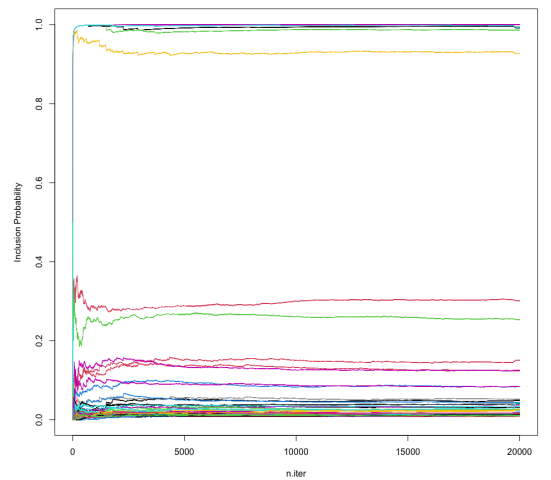

Figure 5: EA peripheral countries trace estimation

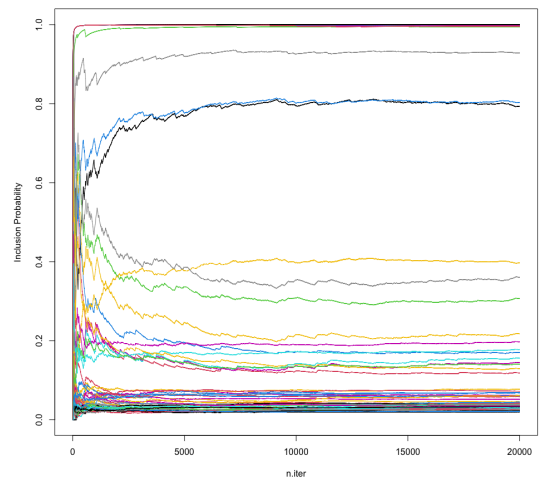



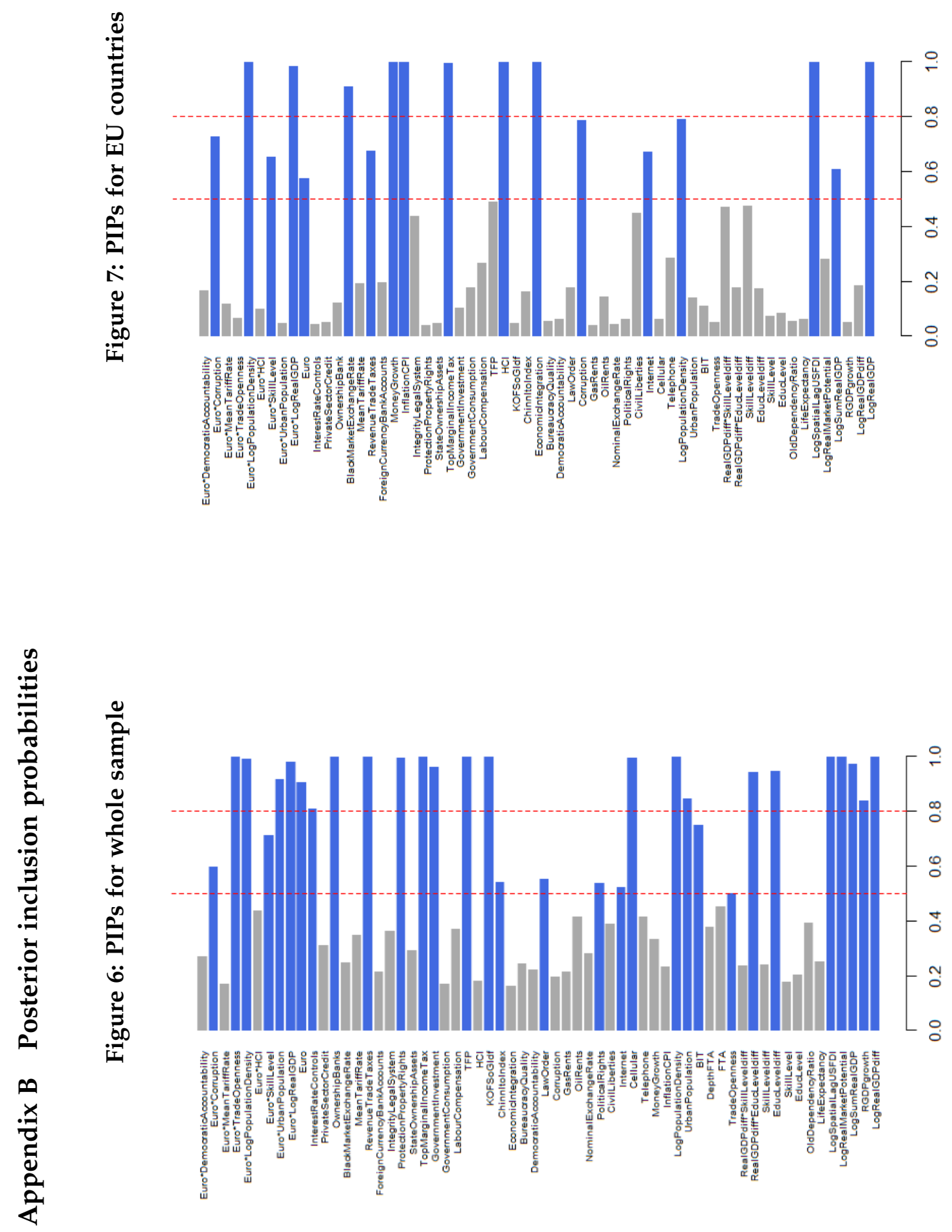

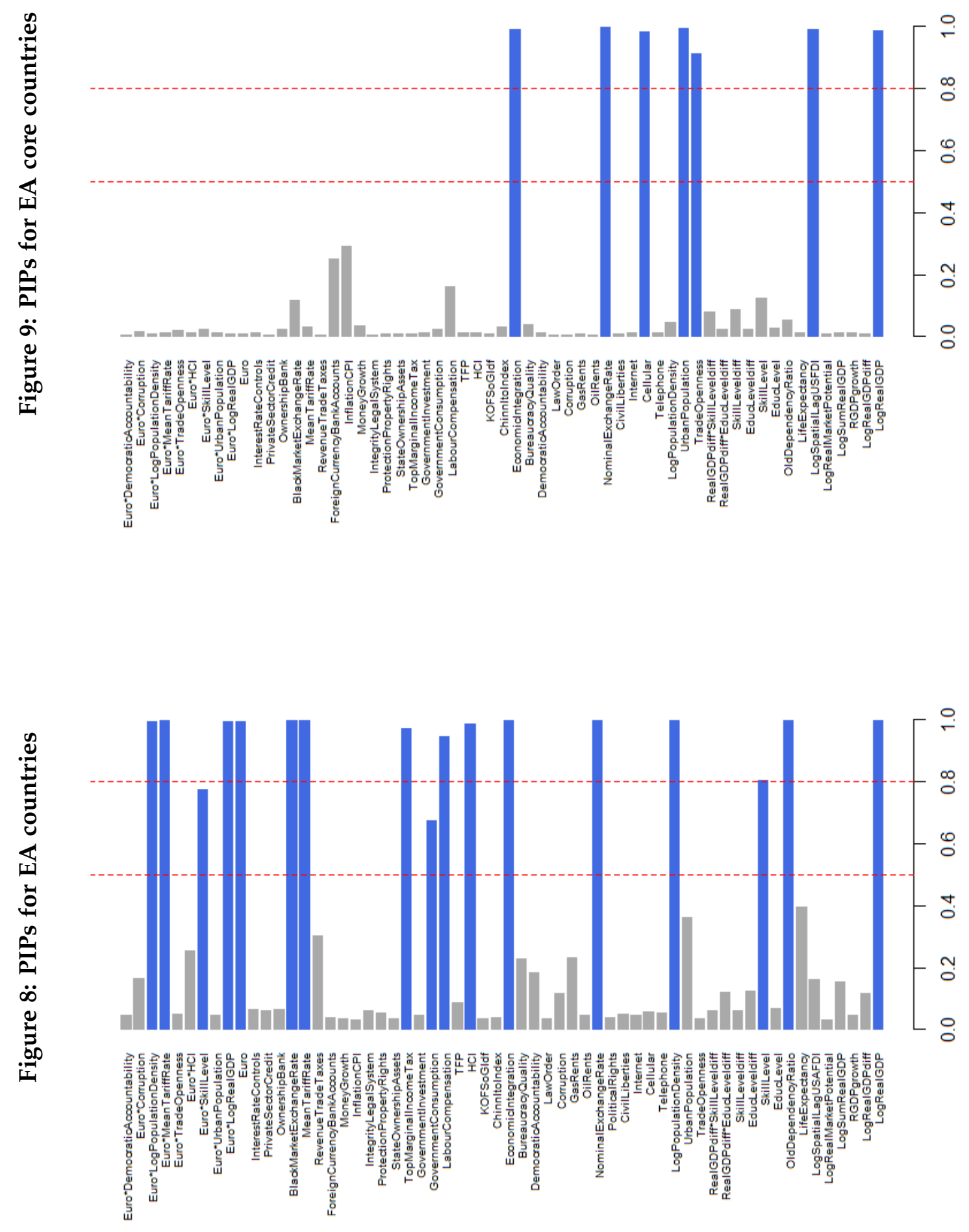
Figure 10: PIPs for EA peripheral countries

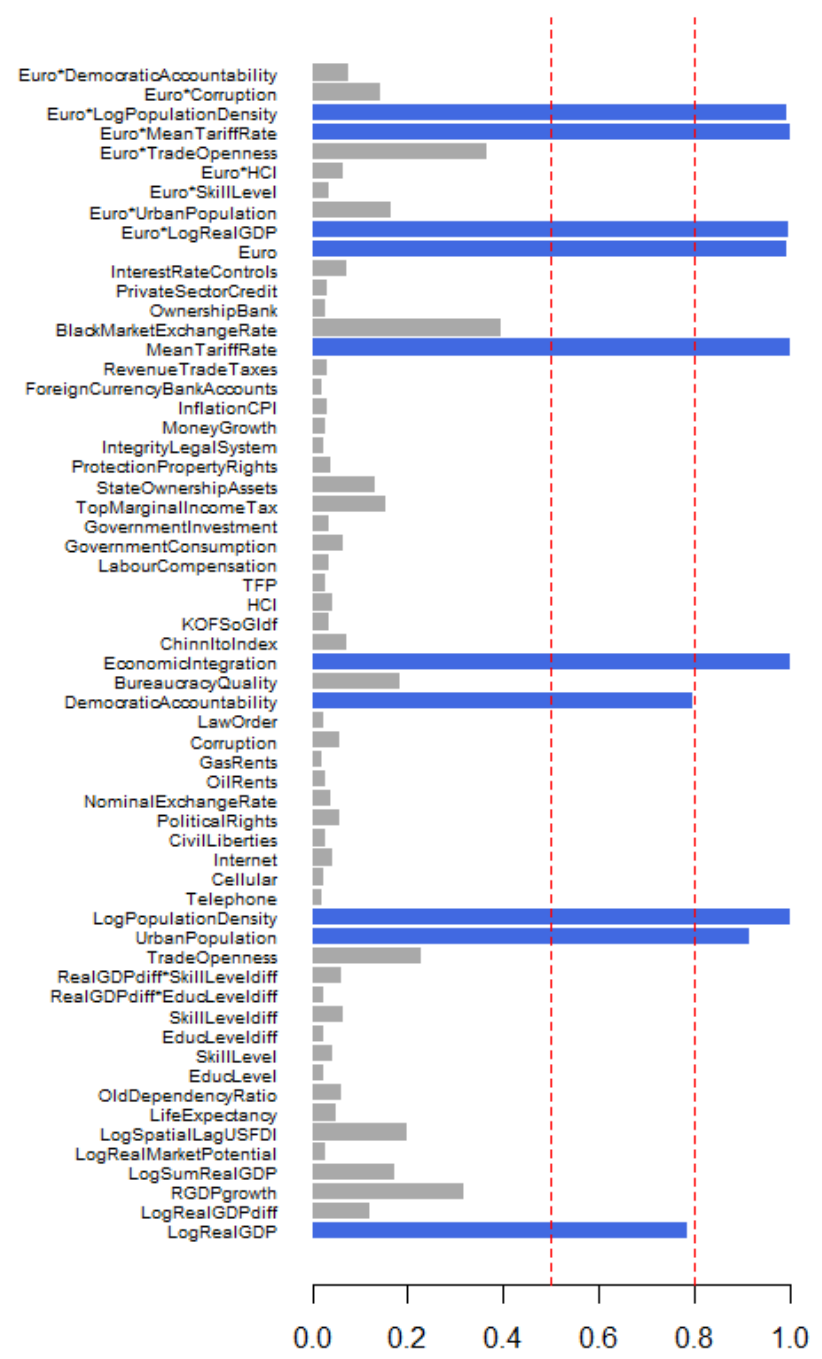

